\title{
Evolución del hecho religioso en el marco del constitucionalismo español 1812-1978
}

\author{
Evolution of the religious fact in the frame work of the Spanish \\ constitutionalism 1812-1978
}

\author{
Enrique Somavilla Rodríguez1 \\ CTSA \\ enrisom@gmail.com \\ Recepción: 06/11/18 Revisión: 16/11/18 Aceptación: 20/11/18 Publicación: 28/11/18
}

\section{RESUMEN}

Las relaciones entre la Iglesia y el Estado han estado vinculadas a los avatares de la historia de España y por los avatares que ha pasado la sociedad española, en las distintas épocas, desde constitucionalismo español, especialmente desde los siglos XIX al XXI. No hay que olvidar que la esencialidad de lo que consideramos hoy nación española está estrechamente vinculada a la creencia y pertenencia a la Iglesia católica desde tiempo inmemorial, incluso durante la dominación árabe, y que se concretará en el reinado de los Reyes Católicos. Es notorio que las influencias cristianas y católicas arraigaron en la mentalidad del pueblo español que unió la fe con su españolidad. Han sido siete Constituciones, tres Cartas otorgadas y otras que no llegaron a promulgarse. Pero la riqueza acumulada en dichas relaciones ha sido determinante a la hora de establecer unos lazos de colaboración entre ambas entidades.

\footnotetext{
${ }^{1}$ Es doctor en Teología Dogmática y en Derecho, licenciado en Estudios Eclesiásticos, Máster en Doctrina Social de la Iglesia, Máster en Relaciones Internacionales y Protocolo, Máster en Derecho de la Unión Europea, Diploma de Estudios Avanzados en Derecho (DEA). Es Profesor ordinario de Teología en el Centro Teológico San Agustín CTSA (afiliado a la Pontificia Universidad de Salamanca), donde imparte diversas asignaturas: Análisis Político y Económico, Sacramentos de Iniciación cristiana, Misterio de Dios, Cristología, Iglesias Orientales, Ecumenismo, Doctrina social de la Iglesia. Profesor de Teologíacristiana de las religiones: relaciones interreligiosas, Teología de la Comunicación, en el Estudio Teológico Agustiniano de Valladolid ETAV (Centro Agregado a la Facultad de Teología del Norte, sede de Burgos). Profesor de Derecho Eclesiásticodel Estado en El Real Centro Universitario Escorial-María Cristina, en San Lorenzo de El Escorial (Madrid) adscrito a la Universidad Complutense y Profesor del Master de Protocolo en la Facultad de Derecho de la UNED. Académico Correspondiente de la Real Academia de Jurisprudencia y Legislación.
} 
Palabras clave: Constitución, Concordato, Acuerdos Parciales, Iglesia católica, Laicidad y Laicismo.

\section{Abstract}

The relationships between Church and State have been linked to the vicissitudes of Spanish History and the vicissitudes of Spanish Society, through its diverse periods since the Spanish Constitutionalism, especially since the XIX century, to the XXI century. It cannot be forgotten that the essentiality of what we know as the Spanish Nation is closely linked to the believing and belonging to the Catholic Church since old times, even during the Arabic domain, materialized during the ruling of the Catholic Monarchs. It is remarkable that the Catholic and Christian influences enrooted in the mentality of the Spanish people that united faith with its Spanish identity. It has been seven Constitutions; three Granted Charter and others Charter unpublished. However, the accumulated richness in those relationships has been decisive at the moment of establishing the bow of collaboration between both entities.

Keywords: Constitution, Concordat, Partial Accords, Catholic Church, Laity, Laicism.

\section{Sumario:}

1. Introducción

2. Articulado del hecho religioso en las Constituciones españolas

3. Articulado del hecho religioso en las Cartas otorgadas

4. Articulado del hecho religioso en las Constituciones no promulgadas

5. Sistema concordatario en las relaciones Iglesia-Estado

6. Libertad religiosa en España

7. Balance

8. Conclusión

9. Bibliografía

\section{INTRODUCCIÓN}

La historia del constitucionalismo español es uno de los aspectos más convulsos de la sociedad española a lo largo de estos últimos doscientos años. Ante un estudio exhaustivo de la realidad constitucional española, desde sus principios, podemos afirmar que han existido siete Constituciones: las de 1812, 1837, 1845, 1869, 1876, 1931 y 1978. Como cartas otorgadas podemos considerar al Estatuto de Bayona de 1808, el Estatuto Real de 1834 y las Leyes Fundamentales del franquismo en su conjunto: Fuero del Trabajo de 1938; Ley Constitutiva de las Cortes de 1942; Fuero de los Españoles de 1945; Ley del Referéndum Nacional de 1945; Ley de Sucesión en la Jefatura del Estado de 1947; Ley de los Principios del Movimiento Nacional de 1958 y Ley Orgánica del Estado de 1967. Para completar el análisis, podemos incluir también el resto de las constituciones non-natas que fueron redactadas, 
pero finalmente no fueron promulgadas, como son las de 1856, 1873 y 1883, respectivamente. En España, para regular las relaciones de la Iglesia y el Estado ${ }^{2}$, ya en 1640 se firmó un primer acuerdo denominado Concordia Fachenettientre Felipe IV y Urbano VII, que establecía los límites de la actividad de los nuncios. Bajo el poder del centralismo borbónico los principales puntos de conflicto fueron el Patronato Real o nombramiento de la jerarquía eclesiástica por parte del monarca y el Exequatur o aprobación regia de las disposiciones pontificias. Como consecuencia del reconocimiento papal del archiduque Carlos, Felipe V suspendió las relaciones diplomáticas con la Santa Sede. Sin embargo, para resolver los asuntos más urgentes firmó el acuerdo de El Escorial. El Concordato de 1753, entre Fernando VI y Benedicto XIV, aceptó claramente el Patronato Real, pero se provocó la ruptura a la muerte de Fernando VII en 1833, a causa de la negativa papal a reconocer el nombramiento de algunos obispos mientras estuviera pendiente la guerra civil ${ }^{3}$. Las discrepancias aumentaron con la desamortización de Mendizábal. En 1851 se llegó a un nuevo Concordato, en que se resolvía el problema de la desamortización y se limitaba el Patronato Real. La nueva ruptura por las leyes de desamortización de 1854-56 se solucionó en el convenio adicional de 1859. El nuevo acuerdo estuvo vigente hasta 1931. Las relaciones entre Iglesia y Estado en España se rigieron por el Concordato de 1953, cuya revisión quedó está sometida a estudio a principios de los años 70. Fue a partir de 1976 y 1979, cuando se inicia el nuevo sistema de los llamados Acuerdos Parciales y culminan finalmente con las ayudas de todas las partes: El Estado y la Iglesia ${ }^{4}$. Los modelos de relación entre la Iglesia y el Estado han sido las siguientes:

a) Cesaropapismo o separación o unión de los poderes político y religioso.

b) Estado confesional con religión oficial.

c) Estado aconfesional con religión no oficial.

d) Separación Iglesia-Estado desde la laicidad.

e) Tolerancia religiosa.

f) Libertad religiosa.

g) Intolerancia y persecución religiosa desde el laicismo.

Un aspecto determinante ha sido la interpretación de laicidad ${ }^{5}$ y laicismo, al igual que no se puede confundir e interpretar la expresión de aconfesionalidad con la de laica ${ }^{6}$. Una afirma no poseer una religión oficial y la otra persigue toda expresión religiosa ${ }^{7}$.

\footnotetext{
${ }^{2}$ Cf. J. Martínez de Pisón CaVero, Constitución y libertad religiosa en España, Madrid 2000.

${ }^{3} \mathrm{Cf}$. W. Cole DuRHAM, "La importancia de la experiencia española en las relaciones Iglesia-Estado para los países en transición", en J. MARTínEZ TORRÓN, (COORD.), Estado y religión en la Constitución española y en la Constitución Europea, Actas del Seminario Internacional Complutense celebrado en la Facultad de Derecho de la Universidad Complutense, Madrid, 14 de mayo de 2004, Granada 2006, pp. 43-68.

${ }^{4}$ Cf. Ma del Mar Martín - M. Salido - J. Mạ. VÁzquez GarcíA-Peñuela, Derecho y religión, Granada 2016, pp. 15-28.

${ }^{5}$ Cf. I. MARTín SÁnCHEZ, "La laicidad positiva y su reflejo en los Estados miembros de la Unión europea", en El Derecho Eclesiástico a las Puertas del Siglo XXI: librohomenaje al profesor Juan GotiOrdeñana, Madrid 2006, pp.265-298; A. GonZÁleZ-VARAS IBÁÑEZ, "Las innovaciones de la carta de derechos fundamentales de la Unión Europea en materia de libertad religiosa", en Anuario de laFacultad de Derecho de Ourense 1 (2002) 271-288.
} 


\section{ARTICULADO DEL HECHO RELIGIOSO EN LAS CONSTITUCIONES ESPAÑOLAS}

Aparecen los siguientes articulados en cada una de ellas:

\subsection{Constitución de la Monarquía española, 1812}

Preámbulo: En el nombre de Dios todopoderoso, Padre, Hijo y Espíritu Santo autor y supremo legislador de la sociedad.

Título II: Del territorio de las Españas, su religión y gobierno y de los ciudadanos españoles.

Capítulo II: De la religión

Artículo 12. La religión de la Nación española es y será perpetuamente la católica, apostólica, romana, única verdadera. La Nación la protege por leyes sabias y justas y prohíbe el ejercicio de cualquiera otra ${ }^{8}$.

Las autoridades juran que defenderán y conservarán la religión católica, apostólica y romana, sin permitir otra alguna en el reino (artículo 117, 173, 212). Igualmente hacía referencias a los artículos $46,47,58,71$ y 86 . Hay que tener en cuenta que un tercio de los diputados eran clérigos y las sesiones de las Cortes comenzaban con la celebración de la Misa.

Título IX: De la Instrucción Pública

Artículo 366. En todos los pueblos de la Monarquía se establecerán escuelas de primeras letras, en las que se enseñará a los niños a leer, escribir y contar, y el catecismo de la religión católica, que comprenderá también una breve exposición de las obligaciones civiles.

Si nos situamos ante nuestra historia constitucional se puede advertir que se mantiene una tensión entre confesionalidad del Estado y libertad religiosa, entre la identidad religiosa y secularización, que abarca toda la vida política, económica, educativa y

\footnotetext{
${ }^{6}$ Cf. D. Llamazares Fernández, Derecho de libertad de conciencia l, Libertad de conciencia y laicidad, Madrid $2002^{2}$.

${ }^{7}$ Cf. R. Navarro-Valls, "El principio de cooperación y la laicidad del Estado”, en J. Martínez-Torrón (Ed.), Estado y Religión en la Constitución Española y en laConstitución Europea: Actas del Seminario Internacional Complutense celebrado en laFacultad de Derecho de la Universidad Complutense, Madrid, 14 de mayo de 2004, Granada 2006, pp.31-42; D. LlamAZARES FernáNDEZ, "Laicidad, libertad de conciencia y acuerdos del Estado con las confesiones Religiosas", en D. LLAMAZARES FernÁNDEZ (DIR),Libertad de Conciencia y Laicidad enlas Instituciones y Servicios Públicos, Madrid 2005, pp.7-32.

${ }^{8}$ Cf. F. GonZÁLEZ -DORIA, Historia de las Constituciones de Godoy a Suárez, Madrid 1986, p. 296.
} 
social $^{9}$. La Constitución de $\mathbf{1 8 1 2}$ trató de recoger las ideas del liberalismo revolucionario ${ }^{10}$ : el eje de la soberanía popular, que descansaba en los ciudadanos, en la división de poderes: legislativo, ejecutivo y judicial y la libertad e igualdad como bases del nuevo Estado que se configuraba ante los desastres de la invasión napoleónica ${ }^{11}$.

Con ella se suprimen los Tribunales de la Inquisición, temporalmente, ya que en fue restablecida en 1814 y en 1823, y así se inician los tiempos de las sucesivas desamortizaciones de los bienes de la Iglesia. Pero no por ello, se puede admitir que se sitúen bajo los postulados liberales en materia de libertad religiosa ${ }^{12}$ y en las conflictivas relaciones entre la Iglesia y el Estado ${ }^{13}$.

A partir de la Constitución española de 19 de marzo de 1812, se puede considerar que nació el constitucionalismo español y, al mismo tiempo, sirvió de fiel modelo a las Constituciones latinoamericanas una vez que alcanzaron sus respectivas independencias. Desde el siglo XIX hasta la actualidad, tanto en España como en las distintas Repúblicas Iberoamericanas, cuando se trata de hablar de religión, ha sido referirse a la propia Iglesia católica ${ }^{14}$. Comprender en la actualidad lo que entendemos por libertad religiosa resulta imposible si se desconoce nuestro pasado de estos últimos doscientos años. Esta Constitución marcó un fuerte sistema confesional. Se posicionó con la identificación de la nación española con la religión católica. La soberanía pasaba del Rey a la nación entera ${ }^{15}$. Esto supuso un cambio de mentalidad en todos los diputados de las Cortes de Cádiz pues, además, el debate se producía en medio del asedio de la ciudad andaluza. Las circunstancias y condiciones no fueron las mejores, pero resistieron heroicamente ${ }^{16}$.

La Constitución de 1812, es más conocida popularmente como La Pepa, pues fue promulgada el día de san José. Constaba de 384 artículos, es la más prolija de todas ellas. Su promulgación se debe a las Cortes de Cádiz, que se encontraban reunidas en dicha ciudad,

\footnotetext{
${ }^{9} \mathrm{Cf}$. M. Cantos Casenave - A. Ramos Santana, "Las Cortes de Cádiz y el primer liberalismo. Elites políticas, ideologías, prensa y literatura. Aportaciones y nuevos retos", en Revista Ayer 22 (2012/85) 23-47.

${ }^{10} \mathrm{Cf}$. J. VARela SuAnZes-CARPegna, "La Constitución de Cádiz y el liberalismo español del siglo XIX", enRevista de las Cortes Generales 4 (1987/10) 27-109.

${ }^{11}$ Cf. J. RosSELL, "El concepto y contenido del derecho de libertad religiosa en la doctrinacientífica española y su incidencia en la jurisprudencia del Tribunal Constitucional", enAnuario de Derecho Eclesiástico del Estado 15 (1999) 87-128.

${ }^{12}$ Cf. Ma del M. MARTín García, “Cooperación económica estatal con las confesiones religiosas, libertad religiosa y aconfesionalidad", en Anuario de Derecho Eclesiástico delEstado16 (2000) 309-339.

${ }^{13}$ Cf. A. FERnÁndeZ-CoRonAdo GonzÁlez, Estado y confesiones religiosas: un nuevo modelo de relación: los pactos con las confesiones, leyes 24, 25 y 26 de 1992, Madrid 1995; D. GARCíA-PARDO, El sistema de acuerdos con las confesiones minoritarias en España e Italia, Madrid 1999.

${ }^{14}$ Cf. R. PALOMINo,Religión y derecho comparado,Madrid 2007.

15 Cf. Habrá que dilucidar como se combinó las tendencias constitucionales españolas y afrancesadas http://www.congreso.es/portal/page/portal/Congreso/Congreso/Hist_Normas/ConstEsp1812 1978/Const181 2 Visto 04-05-2018.

${ }^{16}$ Cf. R. NAVARRo-VAlls, "Justicia constitucional y factor religioso", en Estudios Jurídicos en Homenaje al Profesor Vidal Guitarte, Vol. II Castellón de la Plana 1999, pp.691-700.
} 
sitiada por las tropas de Napoleón. Es una clara representación de las ideas liberales de la España de la época y que mantiene un carácter abierto ${ }^{17}$. Esta Constitución no llegaría demasiado lejos, ante los planteamientos absolutistas de Fernando VII, pero fue el primer intento plausible de ordenamiento constitucional moderno.

\subsection{Constitución de la Monarquía española, 1837}

Preámbulo: Doña Isabel II, por la gracia de Dios.

Título I: De los españoles:

Artículo 11. La Nación se obliga a mantener el culto y los ministros de la religión católica que profesan los españoles.

El régimen que instauró la Constitución de 1837 fue el de una Monarquía constitucional. Por un lado, reforzaba los poderes del Rey, ratificando las facultades, que ya preveía el Estatuto Real, de convocatoria y disolución de las Cámara, así como el derecho de veto. Pero, a la vez, subrayaba el carácter limitado de la Monarquía, a través del principio de inviolabilidad del Rey ${ }^{18}$. Aparecen el Congreso de los diputados y el Senado, es decir sistema bicameral $^{19}$.

La Constitución de 1837, es consecuencia de la acción de un gobierno más moderado y que desarrolla una Constitución mucho más breve pues sólo poseía 77 artículos. Abandona el sistema unicameral de la de 1812 y acepta la segunda cámara o Senado. Tuvo capacidad integradora de las ideas liberales y conservadoras. Moderados y liberales ayudaron a su desarrollo. Su tiempo de aplicación fue tan sólo de ocho años.

\subsection{Constitución de la Monarquía española, 1845}

Preámbulo: Doña Isabel II, por la gracia de Dios.

Título I: De los españoles.

Artículo 11. La Religión de la Nación española es la católica, apostólica, romana. El Estado se obliga a mantener el culto y sus ministros.

En el texto Constitucional de 1845 ya no aparece, como en las anteriores, la formula novedosa de la soberanía de la nación, sino que retrocede a la fórmula tradicional histórica de la soberanía compartida entre las Cortes generales y el Rey. De esta manera se

\footnotetext{
${ }^{17}$ Cf. J. SolÉ TURA - E. AJA, Constituciones y períodos constituyentes en España (1808- 1936), Madrid $1977^{21 r}$, pp. 14-15.

${ }^{18} \mathrm{Cf}$. Podemos contrastar el sistema constitucional recogido en las diversas opciones ya vistas antes. Cf. http://www.congreso.es/portal/page/portal/Congreso/Congreso/Hist Normas/ConstEsp1812 1978/Const183 7 Visto 04-05-2018.

${ }^{\overline{19}}$ Cf. J. Pro RuIz, El Estatuto Real y la Constitución de 1837, Valencia 2010.
} 
desarrollaba, el predominio de la Corona ante las demás instituciones mediante la previa prerrogativa de nombrar al jefe de Gobierno, y dándole, al mismo tiempo, el poder de la disolución de las Cortes ${ }^{20}$.

La Constitución de 1845, tras la caída del gobierno moderado de la monarquía de Isabel II, provocándose un tiempo de disensión, desorden y enfrentamientos. Se lleva adelante una nueva Constitución, de índole más conservador que durará veintitrés años. Es una Constitución que no fue el resultado de ningún proceso constituyente. En vez de eso, unas Cortes ordinarias reformaron la Constitución de 1837 de tal forma que dieron lugar a un texto nuevo. Es la Constitución de Isabel II, que había ascendido al trono en 1843.

\subsection{Constitución democrática de la Nación española, 1869}

Título I: De los españoles y sus derechos.

Artículo 21. La Nación se obliga a mantener el culto y los ministros de la religión católica. El ejercicio público o privado de cualquier otro culto queda garantizado a todos los extranjeros residentes en España, sin más limitaciones que las reglas universales de la moral y del derecho. Si algunos españoles profesaren otra religión que la católica, es aplicable a los mismos todo lo dispuesto en el párrafo anterior.

Esta es la Constitución es la que reconoce de hecho en 1869 y por primera vez en España la libertad de culto ${ }^{21}$.La Constitución de 1869 vino a ser así el contrapunto constitucional inmediato de la Revolución de septiembre. De ahí que, los puntos básicos que se consideraban el alma propia de la Revolución del 1968, quedaron recogidos en el texto constitucional: soberanía nacional, sufragio universal, concepción de la Monarquía como poder constituido y declaración de derechos ${ }^{22}$.El 6 de junio de 1869 se promulga la nueva Constitución, de carácter democrático y monárquica, que estará vigente hasta 1873, cuando se proclame la Primera República (1873-1874). Fue un texto que supuso un salto muy importante respecto a la Constitución vigente hasta entonces, la moderada de 1845.

La Constitución de 1869, se promulgó en el mes de junio. Tras la revolución de septiembre, se plantea otra Constitución, conocida como la gloriosa, en la que se proclama que España es una monarquía Es la Constitución de Amadeo de Saboya. Con el paréntesis de la I República de febrero 1873 hasta diciembre de 1874. Fue la más liberal de todas, con influencias de la Constitución norteamericana de 1787 y a la cabeza de las europeas. Duro sólo siete años. Marcada por los períodos de inestabilidad política que sucedieron a tal promulgación.

\footnotetext{
${ }^{20}$ Cf. J. I. MARCUello Benedicto, La Constitución de 1845, Madrid 2007.

${ }^{21}$ Cf. M. PÉrez LeDESMA, La Constitución de 1869, Madrid 2010.

${ }^{22}$ Cf. La revolución de 1868 produjo grandes quebrantos en la sociedad española del momento. http://www.congreso.es/portal/page/portal/Congreso/Congreso/Hist Normas/ConstEsp1812 1978/Const186 $\underline{9}$ Visto 04-05-2018.
} 


\subsection{Constitución de la Monarquía española, 1876}

Preámbulo: Don Alfonso XII, por la gracia de Dios.

Título I: De los españoles y sus derechos.

Artículo 11. La religión católica, apostólica, romana, es la del Estado. La Nación se obliga a mantener el culto y sus ministros. Nadie será molestado en el territorio español por sus opiniones religiosas ni por el ejercicio de su respectivo culto, salvo el respeto debido a la moral cristiana. No se permitirán, sin embargo, otras ceremonias ni manifestaciones públicas que las de la religión del Estado.

Tras un largo y complejo proceso de elaboración de la Constitución de 1876, su encaje dentro del constitucionalismo histórico español, además de sus rasgos básicos, se relaciona a la cuestión de la soberanía, del reconocimiento y la garantía de los derechos; a la organización de los poderes del Estado y a su estructura territorial. La andadura de la Constitución de 1876 a lo largo de su casi medio siglo de vigencia la ha hecho la más longeva de toda la historia del constitucionalismo español ${ }^{23}$.La Constitución de 1876 es un texto breve y abierto de 89 artículos, que permite mantener la alternancia de partidos ${ }^{24}$. Un sistema de Monarquía constitucional donde el Gobierno cuente con la confianza tanto del rey como parlamentaria. Aprobada el 6 de junio de 1869 se promulga la nueva Constitución, de carácter democrático y monárquica, que estará vigente hasta 1873, cuando se proclame la Primera República (1873-1874). Fue un texto que supuso un salto muy importante respecto a la Constitución vigente hasta entonces, la moderada de $1845^{25}$.

La Constitución de 1876, fue promulgada el 30 de junio de este año. Fue una carta pactada y no impuesta y que permitiría a los dos principales partidos de la Restauración a turnarse en el ejercicio del poder. Estuvo en vigor cuarenta y siete años si se cuentan hasta la implantación del gobierno del General Miguel Primo de Rivera y sesenta y cinco, si se cuenta hasta la caída de la monarquía de Alfonso XIII, en 1931. De hecho, el General Berenguer, al hacerse cargo del gobierno en 1930, intenta volver a los cauces de dicha Constitución, lo que se hace inviable. Por eso casi todos concluyen con esa cifra de cuarenta y siete años. Es la más larga de nuestro sistema constitucional, hasta la actualidad.

\footnotetext{
${ }^{23}$ Cf. J. Varela SuAnzes-Carpegna, La Constitución de 1876, Madrid 2009; J. Tomás Villarroya, Breve historia del constitucionalismo español, Madrid 1982; F. PUY MUÑOz, (COORD.), Los derechos en el constitucionalismo histórico españo/Santiago de Compostela 2002.

${ }^{24}$ Cf. Ha sido de las Constituciones más estables que ha tenido la sociedad española junto con la de 1978. http://www.congreso.es/portal/page/portal/Congreso/Congreso/Hist Normas/ConstEsp1812 1978/Const187 6 Visto 04-05-2018.

${ }^{25}$ Cf. C. GARCíA Prous, “Libertad y tolerancia religiosa en la Constitución de 1876”, en A. Bullón DE MENDOZA Y L. E. Togores (Eds.), Cánovas y su Época: Actas delCongreso, Madrid 20-22 noviembre de 1997, Actas I (1999) 519532.
} 


\subsection{Constitución de la II República española, 1931}

Título preliminar: Disposiciones generales.

Artículo 3. El Estado español no tiene religión oficial.

Título I: Organización nacional

Artículo 14. Son de la exclusiva competencia del Estado español la legislación y la ejecución directa en las materias siguientes:

2ª. Relación entre las Iglesias y el Estado y régimen de cultos.

Título III: Derechos y deberes de los españoles.

Capítulo I: Garantías individuales y políticas.

Artículo 26. Todas las confesiones religiosas serán consideradas como Asociaciones sometidas a una ley especial. El Estado, las regiones, las provincias y los Municipios, no mantendrán, favorecerán, ni auxiliarán económicamente a las Iglesias, Asociaciones e Instituciones religiosas. Una ley especial regulará la total extinción, en un plazo máximo de dos años, del presupuesto del Clero.

Realidad ejercida, que conculcó un derecho fundamental de la persona.

Quedan disueltas aquellas Órdenes religiosas que estatutariamente impongan, además de los tres votos canónicos, otro especial de obediencia a autoridad distinta de la legítima del Estado. Sus bienes serán nacionalizados y afectados a fines benéficos y docentes. Las demás Órdenes religiosas se someterán a una ley especial votada por estas Cortes Constituyentes y ajustada a las siguientes bases:

1. Disolución de las que, por sus actividades, constituyan un peligro para la seguridad del Estado.

2. Inscripción de las que deban subsistir, en un Registro especial dependiente del Ministerio de justicia.

3. Incapacidad de adquirir y conservar, por sí o por persona interpuesta, más bienes que los que, previa justificación, se destinen a su vivienda o al cumplimiento directo de sus fines privativos.

4. Prohibición de ejercer la industria, el comercio o la enseñanza.

5. Sumisión a todas las leyes tributarias del país.

6. Obligación de rendir anualmente cuentas al Estado de la inversión de sus bienes en relación con los fines de la Asociación.

Los bienes de las Órdenes religiosas podrán ser nacionalizados. 
Artículo 27. La libertad de conciencia y el derecho de profesar y practicar libremente cualquier religión quedan garantizados en el territorio español, salvo el respeto debido a las exigencias de la moral pública ${ }^{26}$.

Los cementerios estarán sometidos exclusivamente a la jurisdicción civil. No podrá haber en ellos separación de recintos por motivos religiosos.

Todas las confesiones religiosas podrán ejercer sus cultos privadamente. Las manifestaciones públicas del culto habrán de ser, en cada caso, autorizadas por el Gobierno.

Nadie podrá ser compelido a declarar oficialmente sus creencias religiosas.

La condición religiosa no constituirá circunstancia modificativa de la personalidad civil ni política salvo lo dispuesto en esta Constitución para el nombramiento de presidente de la República y para ser presidente del Consejo de Ministros.

Capítulo II: Familia, economía y cultura.

Artículo 48. La enseñanza será laica, hará del trabajo el eje de su actividad metodológica y se inspirará en ideales de solidaridad humana.

Se reconoce a las Iglesias el derecho, sujeto a inspección del Estado, de enseñar sus respectivas doctrinas en sus propios establecimientos.

Título V: Presidencia de la República.

Artículo 70. No podrán ser elegibles ni tampoco propuestos para candidatos: (...)

b) Los eclesiásticos, los ministros de las varias confesiones y los religiosos profesos.

En esta Constitución, aparece por primera vez el término "laico", incluso antes que en la Constitución francesa de 1946, pero no referido a la separación entre Iglesia y Estado, sino a la enseñanza estatal. Sin duda, ejerció su proyección laicista, desde la visión de parte de esa sociedad francesa. La Constitución de 1931 es la que más mandatos dedica al asunto religioso, casi el doble que las cinco constituciones anteriores juntas, desde la de 1812 a la de 1876. En efecto, la de 1931 dedica seis artículos al tema. A tenor de lo que disponen, no se puede decir que se tratara de una constitución laica en el sentido de establecer la separación entre Estado e Iglesia, a fin de reconocer y garantizar la libertad religiosa de todos los ciudadanos ${ }^{27}$. Más bien, instauró una confesionalidad antirreligiosa del Estado y sentó las bases jurídicas para proceder contra las organizaciones eclesiales. La República no

\footnotetext{
${ }^{26}$ Los artículos 26 y 27 de la Constitución republicana de 1931, supusieron la puntilla para las relaciones entre la Iglesia y la República, con la salida de la Compañía de Jesus en 1932.

${ }^{27}$ Cf. A. Ollero, España, ¿̇un Estado laico? La libertad religiosa en perspectiva constitucional, Madrid 2005; Cf. S. Nieto NúÑEZ - C. CORRAL SALVADOR, "La garantía de la enseñanza de la religión en los Estados de la Unión Europea y candidatos a ella", en Anuario deDerecho Eclesiástico del Estado 19(2003) 305-343;
} 
supo o no quiso asumir las responsabilidades que llevaba consigo ese enfrentamiento pertinaz y a veces, un tanto violento y que no supo atajar o cortar a tiempo ${ }^{28}$. La ley de Confesiones y congregaciones religiosas ${ }^{29}$ fue otro aspecto muy negativo en las relaciones Iglesia Estado.

La realidad es que poco a poco, la persecución a la comunidad cristiana, en general, y a la católica, en particular, desemboca en una serie de acontecimientos funestos y hostiles para cualquier fiel creyente, por el mero hecho de serlo, vivirlo y practicarlo. Posiblemente eso fue uno de los motivos por los que la segunda República española perdió toda su credibilidad. La persecución religiosa fue uno de los mayores escándalos provocados por la misma República, desde el momento de su implantación, pues la quema de conventos se inició en los primeros días tras la proclamación el 14 de abril de 1931. Difícil coyuntura la que se presentaba y que perduraría durante toda su existencia ${ }^{30}$ hasta acabada la Guerra Civil en abril de 1939.

Una década, oprobiosa la de los años treinta en una sociedad convulsionada por muchas ideas políticas subversivas que llevarían al traste la idea idílica de un nuevo régimen, el republicano, que había concitado muchas esperanzas en el sector más avanzado de aquella sociedad. Una sociedad que demandaba grandes cambios sociales, a los que no supo dar una respuesta ${ }^{31}$.Los artículos 26 y 27 , se aprobaron con 178 votos a favor y 59 en contra. Los votos favorables fueron de socialistas, republicanos de izquierda y del partido Republicano Radical. El Republicano progresista, antigua derecha liberal de Alcalá-Zamora y de Maura, la derecha católica y los monárquicos votaron en contra. Tal situación provocó a continuación una grave crisis política ${ }^{32}$. El presidente del Gobierno Provisional Niceto AlcaláZamora y otros ministros, presentaron su dimisión, al estar en completo desacuerdo con el texto aprobado. Esta situación hizo que Manuel Azaña Díaz, fuera elegido nuevo presidente del Gobierno Provisional de la República ${ }^{33}$. La grave inestabilidad del mismo llevó una serie de lastres que no superó en todo el proceso ni constituyente ni la historia del parlamentarismo español, que posicionó a la misma República, saliendo de su neutralidad y escorándose progresivamente hacia un grave precipicio del cual, cuando quiso salir, era ya

\footnotetext{
${ }^{28}$ Cf. S. JULIÁ, La Constitución de 1931, Madrid 2009.

${ }^{29}$ Cf. Ley 2 de junio de 1933, sobre Régimen de la Confesiones y congregaciones religiosas, Gaceta de Madrid de 3 de junio de 1933, no 154, pp. 1651-1653.

${ }^{30}$ Cf. F. J. ZAMORA GARCíA, Relaciones Iglesia-Estado en la España del Frente Popular, Madrid 2017, pp. 151-187.

${ }^{31}$ Cf. R. GARCíA GARCíA "El derecho de asociación en la historia de derecho eclesiástico: reconocimiento yregulación jurídica de las confesiones religiosas en España: decreto de 1 de noviembre de 1868; Ley de 30 de junio de 1887 y Ley de 2 de junio de 1933 relativa a confesiones y congregaciones religiosas", en Anuario de Derecho Eclesiástico del Estado 22 (2006) 161-202.

${ }^{32}$ Cf. Ma DEL C. FRÍAS GARCíA, Iglesia y Constitución: la jerarquía católica ante la II República, Madrid 2000.

${ }^{33}$ Cf. J. BÉCARUD, La Segunda República española, Madrid 1967, pp. 89-111.
} 
demasiado tarde, sin haber conseguido los fines que se propuso cuando las fuerzas políticas se reunieron en San Sebastián en $1930^{34}$.

La Constitución de 1931, después de las elecciones a Constituyentes del 28 de junio, en la primera vuelta y en segunda vuelta entre el 19 de julio y el 8 de noviembre, queda aprobada el 9 de diciembre del mismo año. Es la Constitución de la II República española. En cuanto a su vigencia, ocurre como el caso anterior, si se cuenta hasta el inicio de la Guerra Civil (1936-1939), son sólo cinco años de vigencia y se acepta hasta el final de la contienda no llega a los ocho años de vigencia.

\subsection{Constitución española, 1978, llamada la del Consenso}

Título I: De los derechos y deberes fundamentales.

Capítulo II: Derechos y libertades

Artículo 14. Los españoles son iguales ante la ley, sin que pueda prevalecer discriminación alguna por razón de nacimiento, raza, sexo, religión, opinión o cualquier otra condición o circunstancia personal o social.

Sección I: De los derechos fundamentales y de las libertades públicas ${ }^{35}$.

Artículo 16.

"1. Se garantiza la libertad ideológica, religiosa y de culto de los individuos y las comunidades sin más limitación, en sus manifestaciones, que la necesaria para el mantenimiento del orden público protegido por la ley.

2. Nadie podrá ser obligado a declarar sobre su ideología, religión o creencias.

3. Ninguna confesión tendrá carácter estatal. Los poderes públicos tendrán en cuenta las creencias religiosas de la sociedad española y mantendrán las consiguientes relaciones de cooperación con la Iglesia Católica y las demás confesiones".

Artículo 27, 3‥ Los poderes públicos garantizan el derecho que asiste a los padres para que sus hijos reciban la formación religiosa y moral que esté de acuerdo con sus propias convicciones.

España y la Santa Sede suscribieron una serie de Acuerdos parciales ${ }^{36}$, sobre aspectos de interés mutuo. Suprimían de hecho el Concordato de 1953. Hay que tener en cuenta las

\footnotetext{
${ }^{34}$ Cf. A. Molero PINTAdo, “Laicismo y enseñanza durante la Segunda República Española”, en D. LLAMAZARES FERNÁNDEZ (ED.),Estado y Religión: proceso desecularización y laicidad: homenaje a don Fernando de los Ríos,Madrid2001, pp.141-164; F. DE MEER, “De la república laica a la monarquía parlamentaria aconfesional, pasando por un Estado católico", en C. IzQUIERdo - C. SOlER (EdS.),Cristianos yDemocracia,Pamplona2005, pp.169-189.

${ }^{35}$ Cf. G. DíAz MERChÁN, “El derecho a la libertad religiosa y la Constitución de 1978: en el XXV aniversario de la Constitución", en Constitución Española de 1975 en su XXVAniversario,Barcelona 2003, pp.511-520.
} 
vicisitudes atravesadas por todo el elenco de Constituciones que han recogido el hecho religioso y la libertad religiosa desde los aires de la mentalidad de cada tiempo. A veces adelantadas a su tiempo y entorno y en otras totalmente llevadas adelante con criterios poco objetivos y de respecto a la cuestión religiosa ${ }^{37}$. En cuanto a los instrumentos de gobierno, la Monarquía es aceptada en su modalidad parlamentaria y obviamente entendida como forma de Estado más que como forma de Gobierno, de acuerdo con la doctrina constitucional contemporánea, que sitúa a la Corona en la esfera de la influencia y el prestigio más que en la de los poderes políticos específicos ${ }^{38}$. La gran novedad de la Constitución de 1978 es el reconocimiento pleno de las Comunidades Autónomas a las que se refiere ya en su artículo segundo, según el cual la Constitución se fundamenta en "la indisoluble unidad de la Nación española, patria común e indivisible de todos los españoles, y reconoce y garantiza el derecho a la autonomía de las nacionalidades y regiones que la integran" ${ }^{39}$.

La Constitución de 1978, es la Constitución del consenso de todas las fuerzas políticas, supero las discordias y los enfrentamientos de la Guerra Civil ${ }^{40}$. Es la más amplia y abierta de todas las conocidas, pues acepta la unidad indisoluble de España, pero asume el sistema más descentralizado conocido en la historia del sistema constitucional ${ }^{41}$, que asume al mismo tiempo la mayor descentralización conocida hasta el momento, del sistema autonómico ${ }^{42}$. Aquí sólo nos estamos refiriendo a las siete grandes constituciones de la que se ha dotado España a lo largo de su curso constitucional y democrático, entendiendo que sus características son diferentes y son fruto de su realidad social y en el entorno en que se desarrollaron ${ }^{43}$. Con esto queda cerrado todo el panorama del articulado sobre la cuestión religiosa en las diversas Constituciones y cartas otorgadas. Se puede apreciar los sutiles cambios y transformaciones sufridas a lo largo de todo este proceso, en función, como

\footnotetext{
${ }^{36}$ Cf. Se conoce como Acuerdos con la Santa Sede a los Acuerdos entre el Estado Español y la Santa Sede firmados el 3 de enero de 1979 y son cuatro: sobre Asuntos jurídicos, sobre Enseñanza y Asuntos culturales, sobre la Asistencia religiosa a las Fuerzas Armadas y el servicio militar de clérigos y religiosos, y sobre Asuntos económicos.

${ }^{37}$ Cf. Pedro Gómez García, "El laicismo visto en la teoría, en la ley y en la práctica política", enEnsayos de Filosofía, n 5, 2017.

${ }^{38}$ Cf. R. L. BLANCO VALDÉS, Introducción a la Constitución de 1978, Madrid 2006; L. DíEZ-PICAZO y A. E. PeRALES, La Constitución de 1978, Madrid 2008.

${ }^{39} \mathrm{Cf}$. M. Álvarez TARdío,Anticlericalismo y libertad de conciencia: política y religiónen la segunda República española, 1931-1936,Madrid 2002.

40 Cf. C. Amigo Vallejo, "Una transición olvidada", en La Constitución Española de 1978 en su XXV Aniversario,Barcelona 2003, pp.461-465.

${ }^{41}$ Cf. J. VARela SuAnzes-CARPegna, "La Constitución de 1978 en la Historia Constitucional española”, en Revista Española de Derecho Constitucional 23 (2003/69) 31-67.

${ }^{42}$ Cf. F. TOMÁs y VALIENTE, "La Constitución de 1978 y la historia del constitucionalismo español", en Anuario de Historia del Derecho Español 50 (1980) 721-751.

${ }^{43}$ Cf. J. A. EsCUdero, Curso de historia del derecho, Madrid 2012; S. Juliá - J. PÉREZ - J. VAldeón, Historia de España, Madrid 2008;H. KelSEN,Teoría general del Estado, Granada 2002;A. NAVAS CASTILlo - F. NAVAS CASTILLO, El Estado Constitucional, Madrid 2009; A. TORRES DEL MORAL, Constitucionalismo histórico español, Madrid 2012; A. TORRES DEL MORAL, Estado de derecho y democracia de partidos, Madrid 2012.
} 
hemos dicho anteriormente, sobre los avatares de los tiempos y las personas. Asimismo, la adecuación ante la diferencia entre laicidad y laicismo, respecto a lo que establece la Constitución española de 1978, que garantiza con respecto a la libertad religiosa ${ }^{44}$. Esta situación se abordó de manera muy diferente en la Constitución republicana de 1931, en cuanto al tema religioso fue un conflicto permanente con la Iglesia católica, a pesar de la aceptación de la misma por la jerarquía, los católicos y las instituciones de la misma. El profundo radicalismo unido al rechazo profundo de todo lo que tenía conexión con la vida eclesial, mediante un laicismo altivo y provocador, tuvo pésimas consecuencias para todos ${ }^{45}$. Se puede considerar una gran oportunidad perdida para saber y conocer en profundidadlascomplejasrelacionesentre la Iglesiacatólica y la SegundaRepúblicaespañola, por su arraigadapolítica laicista ${ }^{46}$. Esto determinaríadesdeel principio, por parte de la República, un política de lata beligeranciarespecto de la Iglesiacatólica, cuandodesdelosmismosiniciso, éstaestuvo con elrégimeninstaurado sin ningún tipo de prejuicios y con acatamiento al poderconstituido ${ }^{47}$.

\section{ARTICULADO DEL HECHO RELIGIOSO EN LAS CARTAS OTORGADAS}

Aparecen los siguientes articulados en cada una de ellas:

\subsection{Estatuto de Bayona, 1808}

Preámbulo: En el nombre de Dios Todopoderoso.

Título I: De la religión.

Artículo 1: La religión Católica, Apostólica y Romana, en España y en todas las posesiones españolas, será la religión del Rey y de la Nación, y no se permitirá ninguna otra.

Antes de que se produjese la primera sesión de la Junta de Bayona, Napoleón ya había iniciado el proyecto constitucional que sometería a examen, aunque en realidad este proyecto parece haber nacido de la pluma de Maret. El primer proyecto seguía muy de cerca

\footnotetext{
${ }^{44}$ Cf. A. Ollero TASSARA, "Laicidad y laicismo en el marco de la Constitución española", en A. Ollero Tassara - C. HERMidA del LLANo (CoORDS.), La libertad religiosa en España y en el Derecho comparado, Madrid 2012, pp.17-31. ${ }^{45}$ Cf. F. DE MEER, La cuestión religiosa en las Cortes Constituyentes de la II Repúblicaespañola, Pamplona 1975, p. 15.

${ }^{46}$ Cf. J. DE LA CUEVA, "El anticlericalismo en la SegundaRepública y la Guerra Civil”, en E. La Parra- M. Suárez Cortina (Eds.), El anticlericalismo españolcontemporáneo, Madrid, 1998, pp. 211-301; J. DE LA CUEVA, "El laicismo republicano: tolerancia e intolerancia religiosa en la SegundaRepública", en Melanges de la Casa de Velázquez, 44, (2014/1) 89-109; M. ÁlvarezTARdío, Anticlericalismo y libertad de conciencia. Política y religión en la SegundaRepúblicaespañola, Madrid 2002, pp. 90-96 y 129-132; C. ROBLESMUÑOz, "El Vaticano, el nuncio y losobisposespañoles ante la República de abril de 1931", en J. DE LA CUEVA - F. MONTERO (EDS.), Laicismo y catolicismo. Elconflictopolítico-religioso en la SegundaRepública, Alcalá de Henares 2009, pp. 129-158; C. RoBlesMuÑOZ, "Alcalá Zamora: un republicanodemócrata y un cristiano", en Hispania Sacra, 64, (2012/1) 69148; M. CONTRERASCASADO - J. R. MONTERO GIBERT, "Una constituciónfrágil: revisionismo y reformaconstitucional en la II Repúblicaespañola", en Revista de DerechoPolítico 6 (1981-1982/12) 23-63.

${ }^{47}$ Cf. J. A. GonZÁlez-ARES, Leyes constitucionales españolas 1808-1978, Santiago de Compostela 2011.
} 
el sistema constitucional napoleónico, estando en realidad más próximo a textos como la Constitución de Westfalia o la de Nápoles, que a la realidad política española ${ }^{48}$. Napoleón quiso imponer de facto a su hermano José, en el trono de España, pero eso llevó a la carta otorgada, como predominio de su poder tras la guerra de Independencia de $1808^{49}$.

\subsection{Estatuto Real, 1834}

No menciona absolutamente nada al respecto de la religión, el culto o la Iglesia.

En cambio sí aparece:

Título II: Del Estamento de Próceres del Reino.

Artículo 3. El Estamento de Próceres del Reino se compondrá:

1을 Me Muy Reverendos Arzobispos y Reverendos Obispos.

Artículo 4. Bastará ser Arzobispo u Obispo electo auxiliar para poder ser elegido en clase de tal y tomar asiento en el Estamento de Próceres del Reino ${ }^{50}$.

El Estatuto Real fue una constitución flexible, breve e incompleta ${ }^{51}$. De tan sólo 50 artículos, que regulaban la organización de las Cortes, sus funciones y sus relaciones con el Rey, no recogía ningún título dedicado a la Monarquía ni a sus ministros y, sobre todo, no contenía una declaración de derechos fundamentales del ciudadano. Se trató de una Carta Otorgada 52 .

\subsection{Leyes Fundamentales del Reino: Régimen autoritario del General Franco}

Como su propio nombre indica, no es una Constitución al uso ${ }^{53}$, sino más bien sería un Estatuto al uso. Denominadas por el Régimen Leyes Fundamentales ${ }^{54}$.

48 Cf. http://www.cervantesvirtual.com/obra-visor/la-primera-constitucin-espaola---el-estatuto-de-bayona0/html/ffc6353a-82b1-11df-acc7-002185ce6064 4.html Visto 04-05-2018.

${ }^{49}$ Cf.J. A. González-ARES, Las constituciones de la España contemporánea. De Estatuto de Bayona a las Leyes Fundamentales del franquismo, Santiago de Compostela 2010.

${ }^{50}$ Cf. J. Pro RuIZ, El Estatuto Real y la Constitución de 1837, Valencia 2010.

${ }^{51}$ Cf. T. Zamora Rodríguez, F. J. Zamora García, J. Rodríguez Fernández, F. MARHuenda García, R. CANOSA USERA - J. J. GONZÁlEZ RIVAS, El constitucionalismo frustrado. Proyectos españoles de 1834 a 1976, Madrid 2014, pp. 44-62.

${ }^{52} \mathrm{Cf}$. Carta otorgada como una dejación voluntaria de los poderes por parte de la Corona.

${ }^{53} \mathrm{Cf}$. P. Martín de SANTA Olalla Saludes, La Iglesia que se enfrentó a Franco: Pablo VI, la Conferencia Episcopal y elConcordato de 1953, Madrid 2005.

${ }^{54} \mathrm{Cf}$.Leyes Fundamentales del Régimen del General Franco se denominan al conjunto de leyes principales del Estado franquista y que, en ausencia de una Constitución, sostenían jurídicamente a la dictadura, y son las siguientes: Fuero del Trabajo (1938), Ley Constitutiva de las Cortes (1942), Fuero de los Españoles (1945), Ley del Referéndum Nacional (1945), Ley de Sucesión en la Jefatura del Estado (1947), Ley de Principios del Movimiento Nacional (1958) y Ley Orgánica del Estado (1967). 


\subsection{Fuero del trabajo, 1938}

Preámbulo: "Renovando la tradición católica de justicia social..."

Artículo I.3. El derecho de trabajar es consecuencia del deber impuesto al hombre por Dios.

Artículo II.2. El Estado mantendrá el descanso dominical como condición sagrada en la prestación del trabajo.

Artículo II.3. Sin pérdida de la retribución y teniendo en cuenta las necesidades técnicas de las empresas, las leyes obligarán a que sean respetadas las fiestas religiosas y civiles declaradas por el Estado.

\subsection{Fuero de los Españoles, 1945}

Reformado por la Ley Orgánica del Estado de 10 de enero de 1967.

Está calcado, casi al pie de la letra, de artículo 11 de la Constitución de 1876.

Preámbulo: El Fuero de los Españoles, texto fundamental definidor de los derechos y deberes de los mismos y amparador de sus garantías; y teniendo en cuenta, al igual que ocurre en el Fuero del Trabajo, que sus líneas maestras acreditan el valor permanente del ideario que las inspira y gran número de sus declaraciones y preceptos constituyen un fiel anticipo de la doctrina social-católica, recientemente puesta al día por el Concilio Vaticano II y finalmente, dada la modificación introducida en su Artículo 6 por la Ley Orgánica del Estado, aprobada previo referéndum de la Nación, a los efectos de adecuar su texto a la Declaración Conciliar sobre la libertad religiosa, promulgada el 1 de diciembre del año 1965, que exige el reconocimiento explícito de este derecho, en consonancia, además, con el segundo de los Principios Fundamentales del Movimiento, según el cual la Doctrina de la Iglesia habrá de inspirar nuestra legislación.

Artículo 6. La profesión y práctica de la Religión Católica, que es la del Estado español, gozará de la protección oficial.

El Estado asumirá la protección de la libertad religiosa, que será garantizada por una eficaz tutela jurídica que, a la vez, salvaguarde la moral y el orden público. Nadie será molestado por sus creencias religiosas ni el ejercicio privado de su culto. No se permitirán otras ceremonias ni manifestaciones externas que las de la Religión católica.

\subsection{Ley de Principios del Movimiento Nacional, 1958}

Preámbulo: Yo, Francisco Franco Bahamonde, Caudillo de España, consciente de mi responsabilidad ante Dios y ante la Historia, en presencia de las Cortes del Reino, promulgo como Principios del Movimiento Nacional, entendido como comunión de los españoles en los ideales que dieron vida a la Cruzada, los siguientes: 
II. La Nación española considera como timbre de honor el acatamiento a la Ley de Dios, según la doctrina de la Santa Iglesia Católica, Apostólica y Romana, única verdadera y fe inseparable de la conciencia nacional, que inspirará su legislación.

VII. El pueblo español, unido en un orden de Derecho, informado por los postulados de autoridad, libertad y servicio, constituye el Estado Nacional. Su forma política es, dentro de los principios inmutables del Movimiento Nacional y de cuanto determinan la Ley de Sucesión y demás Leyes fundamentales, la Monarquía tradicional, católica, social y representativa.

IX. Todos los españoles tienen derecho: (...) 4. A una equitativa distribución de la renta nacional y de las cargas fiscales. El ideal cristiano de la justicia social, reflejado en el Fuero del Trabajo, inspirará la política y las leyes.

El general Franco durante su mandato autoritario, fue muy reacio a fijar en exceso y con detalle y rigor, las atribuciones del poder y se opuso frontalmente a una Constitución que recordase el período liberal. Cuando se decidió a institucionalizar su gobierno personal, fue como respuesta a acontecimientos externos y a presiones de quienes querían asegurarse la continuidad del franquismo en España. Ello obligó a promulgar un conjunto de leyes complejas, y contradictorias, que aparecían según las necesidades políticas que atravesaba el régimen, según las épocas y circunstancias del momento ${ }^{55}$. A falta de un sistema constitucional propiamente dicho, dotó al Estado de una serie de Leyes Fundamentales. Tras la muerte de Franco, otra ley será aprobada con rango de Ley Fundamental, la Ley para la Reforma Política de 1977 que, en realidad, establece las condiciones mínimas para escoger las Cortes mediante el sufragio universal y habilita por el mismo procedimiento a la reforma constitucional de las Leyes Fundamentales del Reino. Las Leyes Fundamentales del Reino, o del Estado español fueron el conjunto de siete leyes que organizaban los poderes del Estado durante el gobierno del general Francisco Franco. Durante la transición española, en 1977, se realizó una octava ley con el mismo rango para modificar el marco legislativo y poder llevar a cabo la reforma política ${ }^{56}$. Todas ellas fueron derogadas al aprobarse y entrar en vigor la Constitución Española de 1978.

\section{ARTICULADO DEL HECHO RELIGIOSO EN LAS CONSTITUCIONES NO PROMULGADAS}

\section{Constitución non nata, 1856}

Establecía claramente los siguientes aspectos:

Título I: De la Nación y de los españoles.

\footnotetext{
55 Cf.M. Á. Giménez MARTínez, El Estado franquista. Fundamentos Ideológicos, bases legales y sistema institucional, Madrid 2014, p. 37.

${ }^{56}$ Cf. T. FeRnÁNDEZMIRANDA, Elhombreylasociedad, Madrid1966.
} 
Artículo 14: La Nación se obliga a mantener y proteger el culto y los ministros de la religión católica que profesan los españoles. Ningún español ni extranjero podrá ser perseguido por sus opiniones o creencias religiosas, mientras no las manifieste por actos públicos contrarios a la religión.

El proyecto de $1856^{57}$ es uno de los dos intentos fallidos de renovación constitucional en nuestra historia del siglo XIX. Por eso, constituye un momento del pasado sumamente atractivo y prometedor cuya importancia no ofrece la menor duda ${ }^{58}$.

\section{Constitución no-nata, 1873}

Es la Constitución Federal de la I República Española, que establecía:

Título II: De los españoles y sus derechos.

Artículo 34: El ejercicio de todos los cultos es libre en España

Artículo 35. Queda separada la Iglesia del Estado.

Artículo 36. Queda prohibido a la nación o al Estado federal, a los Estados regionales y a los Municipios subvencionar directa ni indirectamente ningún culto.

Artículo 37. Las actas de nacimiento, de matrimonio y defunción serán registradas siempre por las autoridades civiles.

El proyecto constitucional federal de $1873^{59}$ es, por otro lado, un nuevo y ambicioso intento de modernización institucional tendente a resolver problemas endémicos de nuestro constitucionalismo que, de haber fructificado, nos hubiera situado en presencia de una de las Constituciones más innovadoras y avanzadas de la época ${ }^{60}$.

\section{Constitución Federal nonata, 1883}

Planteaba el sentido federal y establecía:

Título II: Derechos que la Federación garantiza.

Artículo 2. El derecho a la libre emisión, manifestación y difusión del pensamiento y el derecho a la libre expresión de la conciencia y al libre ejercicio de los cultos.

\footnotetext{
${ }^{57}$ Cf. T. Zamora Rodríguez, F. J. Zamora García, J. Rodríguez Fernández, F. MARHuenda García, R. CANOSA USERA - J. J. GONZÁlEZ RIVAS, El constitucionalismo frustrado. Proyectos españoles de 1834 a 1976, Madrid 2014, pp. 124-150. ${ }^{58} \mathrm{Cf}$. I. CASANOVA AGUILAR, Las constituciones no promulgadas de 1856 y 1873, Madrid 2008.

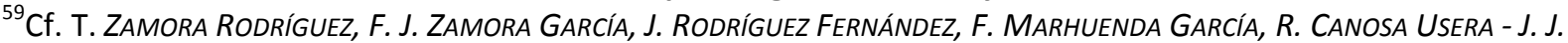
GonZÁlez RIVAS, El constitucionalismo frustrado. Proyectos españoles de 1834 a 1976, Madrid 2014, pp. 151-183. ${ }^{60} \mathrm{Cf}$. I. CASANOVA AGUILAR, Las constituciones no promulgadas de 1856 y 1873, Madrid 2008.
} 
Artículo 6. Ni la Federación, ni los Estados regionales, ni los Municipios podrán sostener culto alguno.

Artículo 7. Las actas de nacimiento, las de matrimonio y las de defunción deberán ser registradas por las autoridades civiles de los Estados respectivos; sólo serán válidas las que tengan este requisito.

Artículo 8. Quedan secularizados todos los cementerios.

Artículo 9. Quedan secularizadas la enseñanza y la beneficencia, ya dependan de la Federación, ya de los Estados regionales, ya de las Municipalidades.

Fue un proyecto de Constitución federal redactada por Francisco Pi y Margall, en 1883. Insistió siempre es que la Federación tenía encargada la custodia de los derechos fundamentales de las personas. Él hablara del "derecho humano en todas sus manifestaciones" ${ }^{\prime 1}$. Claro en cuanto al tema de la libertad de cultos del artículo 2, quedaba mediatizado por los artículos 6,7 y 8 respectivamente, y que, por tanto, ya lo matizaba rigurosamente en su desarrollo. No hubiera sido una Constitución al uso en estos temas que los desarrollaba de manera radicalizada.

\section{SISTEMA CONCORDATARIO EN LAS RELACIONES IGLESIA-ESTADO}

El sistema de relaciones entre la Iglesia y el Estado han sido muy variadas a lo largo del tiempo. La libertad ideológica, religiosa y de culto, se configura como un derecho, y debe ser objeto de consideración por parte del Estado. La regulación estatal de la libertad ideológica y religiosa "exige la previa determinación de la posición jurídica del Estado ante el fenómeno ideológico-religioso asentado en su territorio" ${ }^{\prime 22}$. Europa ha sido determinante a la hora de emplazar definitivamente este tema ${ }^{63}$.La relación de los Estados y el fenómeno religioso ha dado lugar a los distintos modelos de relación: identidad, exclusividad, utilidad en forma de Estado confesional o de Religión de Estado y neutralidad ${ }^{64}$. Es fundamental tener en cuenta el sentido del derecho constitucional ${ }^{65}$.

\section{El Concordato de 13 mayo de 1418}

\footnotetext{
${ }^{61}$ Cf. Título II, derechos que la federación garantiza. Cf. J. A. GonzÁlez CASANOVA, Federalismo i autonomía a Catalunya (1868-1938), Barcelona 1974, p. 484.

${ }^{62}$ Cf. J. T. MARtín De AgAR, Raccolta di Concordati 1950-1999, Ciudad del Vaticano 2000.

${ }^{63}$ Cf. R. Ma MARTínez DE CODES, "La religión y la nueva Constitución para Europa”, en Anuario de Derecho Eclesiástico del Estado 21 (2005) 39-47; A. FernándeZ-Coronado GonZÁlez, (Dir.).El derecho de la libertad de conciencia en el marco de la Unión Europea: pluralismo y minorías. Madrid2002; O. CELAdOR ANGón, “Notas para una interpretación sistemática del artículo 6 delTratado de la Unión Europea en materia de libertad de conciencia", en Derechos yLibertades 8 (2003/12) 141-177.

${ }^{64}$ Cf.P. Lombardía - J. Fornés, "El Derecho Eclesiástico", en J. Ferrer OrTIZ, (COORD.), Derecho Eclesiástico del Estado español, Pamplona 2007, pp. 21-52.

${ }^{65}$ Cf. F. MARHUENDA -F. J. ZAMORA García, Fundamentos de Derecho Constitucional, Madrid 2016, pp. 27-39.
} 
El Concordato entre el reino de Castilla y la Santa Sede el 13 de mayo de 1418, siendo rey Juan II, puede considerar como el primer concordato firmado por España, si consideramos a Castilla como el embrión de la nación que se convertirá en una de las más antiguas del continente europeo.

El deseo de reforma estaba muy presente en todos los estamentos de la Iglesia y el Concilio de Constanza se preocupó de ella en el 1418, pero para el papa se trataba sobre todo de reformar la praxis de la Curia romana. Martín V inició negociaciones separadas con las diversas potencias y llevó adelante con cada nación una serie de concordatos que firmó y aplicó con cada una de ellas, iniciándose una nueva política, aunque en el futuro habría mucho por hacer ${ }^{66}$.

Con Martín V se restablece la unidad de la Iglesia tras el horrendo desastre del Cisma de Occidente y volvió a instalar tanto el pontificado como la Curia en Roma. No cedió a las presiones de alemanes y franceses, respecto de instalarse en Alemania o en Francia. Esto supuso a la larga, una mayor capacidad de acción para los distintos pontífices y una buena dosis de paciencia a las demás potencias europeas, que se perfilaban en el panorama de la sociedad del siglo XV y XVI.

\section{El Concordato de 11 de enero de 1753}

El Concordato de 1753 es, sobre todo, un concordato favorecedor, por el que se derogaban todas las reservas pontificias en España, haciéndose a la Monarquía católica concesiones nunca igualadas, hasta entonces al Real Patronato. En él no se aparecen referencias concretas a otros campos de las relaciones entre la Iglesia y el Estado, aunque en el siglo XVIII estaban perfectamente delimitadas las funciones de ambas sociedades. Se procuraba regular la provisión de los beneficios eclesiásticos, resolviendo de un modo definitivo las graves discrepancias sobre el patronato universal. Se deseaba eliminar las reservas pontificias y los gravámenes económicos sobre las rentas beneficiales. Por eso, el Concordato de 1753 fue derogatorio respecto de las reservas pontificias en España; es también el Concordato, el que amplía los derechos de patronato de los Reyes de España; por último, es el Concordato, que establece el punto culminante del regalismo español y, al mismo tiempo, el medio por el que se llevó a la ruptura de la Monarquía Hispánica con la Sede Apostólica ${ }^{67}$.

Tanto en 1717 como en 1737, ya se llegaron a negociar ambos Concordatos, pero fueron rechazados por qué no llegaron a entrar en vigor y además fueron ignorados. El de 1753 fue firmado por su Majestad católica Fernando VI y el papa Benedicto XIV. Su firma se produjo en el Palacio del Quirinal, por el cardenal Valenti y Manuel Ventura Figueroa ${ }^{68}$ y ratificado en la Basílica de Santa María la Mayor. Este fue el auténtico negociador por parte

\footnotetext{
${ }^{66}$ Cf. J. M. NieTo SORIA, “El pontificado de Martín V y la ampliación de la soberanía real sobre la Iglesia castellana (1417-1431)", en La España Medieval 17 (1994) 117-122.

${ }^{67} \mathrm{Cf}$. http://pares.mcu.es/ParesBusquedas20/catalogo/description/5650557 Visto14-12-2018.

${ }^{68}$ Cf. A. Portabales PiCHeL, D. Manuel Ventura Figueroa y el Concordato de 1753, Madrid 1948.
} 
de España ante la Santa Sede ${ }^{69}$. La firma del Concordato de 1753 supuso la asunción de numerosos poderes de la Iglesia por parte del Rey, que pasaba así a controlar la misma. El Concordato de 1753 siguió en vigor casi un siglo hasta la firma del nuevo Concordato de 1851 , aunque se suspendió ante la ruptura de relaciones diplomáticas en 1833. Como consecuencia del fruto de la doble misión del Nuncio apostólico, la persona del Nuncio será requerida, a petición de las Cortes y de los Reyes, para juzgar las causas eclesiásticas en segunda instancia, Ilamado Tribunal de Apelación. Tal ejercicio, no exento de polémicas y conflictos con la autoridad eclesiástica ordinaria, quedó regulado en el Concordato de 1753, y en concreto, con la creación del Tribunal de la Rota española o Tribunal de la Rota de la Nunciatura Apostólica de Madrid, todavía en activo y en beneficio de la Iglesia católica en España $^{70}$.

Debido a la política emprendida por Fernando VI fue posible también, en otro orden de cosas, la restauración de las relaciones cordiales con la Iglesia. EI Santo Padre Clemente XI había reconocido como Rey de España al archiduque Carlos de Austria en detrimento de Felipe $\mathrm{V}$, lo que había provocado una fuerte tensión en las relaciones hasta un punto del todo insostenible. Pero sería esa política de moderación llevada adelante por Fernando VI, lo que posibilitó el mejor entendimiento con el papa Benedicto XIV, que culminaría con la firma del Concordato de $1753^{71}$. Sería igualmente con este Concordato cuando se consigue el derecho de presentación de Obispos, que lo firmaría José de Carvajal y Lancaster y que había sido concedido a los Reyes Católicos.

\section{El Concordato de 16 de marzo de 1851}

Las relaciones diplomáticas entre España y la Santa Sede mejoraron ostensiblemente al estar al frente como presidente del Consejo de Ministros de España, la figura de Juan Bravo Murillo. Tras las intensas negociaciones, llevadas a cabo desde 1845, se llegó a un primer acuerdo entre España y la Santa Sede, en el que diseñaron aportaciones a las dos cuestiones que generaban más fricciones en ese momento: la provisión de las sedes vacantes y la dotación económica de la Iglesia. La llegada de Pío IX, un papa mucho más flexible que el anterior, Gregorio XVI, imprimió cierto dinamismo al proceso negociador. Hay que tener en cuenta, que las tropas españolas colaboraron para que el Santo Padre recuperara el poder temporal después de la experiencia revolucionaria que había llevado al establecimiento de la república romana. Por fin, el 16 de marzo de 1851 se llegó a la firma del deseado Concordato ${ }^{72}$. Serán sus artífices el papa Pío IX y su Majestad católica Isabel II, Reina de las Españas.

\footnotetext{
69 Cf. Ma. J. Martínez JimÉneZ, "Relaciones Iglesia-Estado. El Concordato de 1753", en Hispania Sacra 52 (2000/105) 301-310.

${ }^{70} \mathrm{Cf}$. http://www.nunciaturapostolica.es/nunciatura-es.html Visto 04-05-2018.

${ }^{71}$ Cf. Concordato celebrado en 1753 entre las cortes de Roma y Madrid, Madrid 1763, Imprenta Antonio Pérez de Soto, pp. 1-34: especialmente p. 27.

${ }^{72}$ Cf. http://www.andalan.es/?p=12806 Visto 04-05-2018.
} 
De aquí que, "el Concordato de 1851 va a establecer las nuevas bases de funcionamiento, y potencial crecimiento, de la Iglesia en la España gobernada por la oligarquía liberal. Los enfrentamientos frontales que las autoridades eclesiásticas habian protagonizado frente al nuevo régimen darán paso a una actitud más posibilista, lo cual permitirá ir asumiendo los espacios de influencia abiertos en el texto concordatario. Poco a poco, y no sin algún que otro contratiempo, la jerarquía católica se va a ir encontrando más cómoda en el nuevo Estado, estableciendo sólidos lazos con un sector de la oligarquía dominante con el cual, vencidos los mutuos recelos de la primera época, constituirá una sólida estructura ideológica, con escasos márgenes de tolerancia a la disidencia, que permitirá a la Iglesia desplegar toda su influencia social y política en los años de la Restauración, durante los cuales se habrán de dirimir duras batallas frente a los sectores que se obstinan en reclamar mayores cotas de libertad de pensamiento" ${ }^{73}$.

Este Concordato fue ratificado en el palacio de Madrid el día 1 de abril de mil ochocientos cincuenta y uno, y en Roma el 23 del mismo mes y año, habiendo sido canjeadas las ratificaciones en el mismo palacio en 11 de mayo del mismo año. El 5 de septiembre siguiente expidió Su Santidad las letras apostólicas sobre el citado Concordato, las cuales se mandaron publicar en la forma ordinaria el 17 de octubre del referido año, remitir un ejemplar con real cédula a los Muy Reverendos arzobispos, Reverendos obispos, abades, etc., para que se conserven en sus respectivos archivos, así como se mandó el mismo día a todos los tribunales y autoridades civiles, militares, eclesiásticos, etc., y guardar, y hacer guardar en todas sus partes la ley del Concordato ${ }^{74}$.

Debido a todo el proceso de la desamortización, llevado a cabo por Juan Álvarez Mendizábal a partir de 1835 y la consiguiente abolición del diezmo en 1851, se firma el Concordato con la Santa Sede, en el que se procedía la suspensión de la venta de todos los bienes eclesiásticos desamortizados y el retorno de los no vendidos ${ }^{75}$. A cambio, la Santa Sede reconocía a Isabel II y aceptaba la obra desamortizadora, mientras el Estado se comprometía al sostenimiento de la Iglesia española.

\section{El Concordato de 27 de agosto de 1953}

El Concordato entre España y la Santa Sede de 1953 fue firmado en la Ciudad del Vaticano, el 27 de agosto, por el secretario de Estado, de la Santa Sede Domenico Tardini, Alberto Martín Artajo, ministro de Asuntos Exteriores y Fernando María Castiella y Maíz, embajador de España ante la Santa Sede.

\footnotetext{
${ }^{73}$ M. FernÁndez RierA, Rosario de Acuña y Villanueva. Una heterodoxa en la España del Concordato, Gijón 2009, p. 16.

${ }^{74}$ Cf. Ministerio de EstAdo, Ratificación del Concordato de 1851, en Gaceta de Madrid no 6146(12-05-1851), pp. 1-4.

${ }^{75}$ Cf. Ma del M. LeAL AdoRnA, “Los principios del derecho eclesiástico según lainterpretación de la doctrina española”, en Anuario de Derecho Eclesiástico del Estado, 17 (2001) 35-100; J. FerRER ORTIZ, (CoORD.), Derecho eclesiástico del Estado español, Pamplona $1996^{4}$.
} 
El embrión de dicho Concordato, fue el Acuerdo firmado el 7 de junio de 1941, que prefiguraba, en una gran medida, la parte esencial del mismo: plena libertad y concesiones para la Iglesia católica a cambio de que el jefe del Estado conservara el privilegio de Presentación los obispos y el privilegio de Fuero eclesiástico, con el ánimo de contar con una jerarquía proclive al Régimen autoritario del general Franco en España ${ }^{76}$. De parte del Estado se recogían dos aspectos fundamentales: confesionalidad del mismo y la negación de la libertad religiosa. Los artículos 9, comprometiéndose el Gobierno español a observar las disposiciones contenidas en los cuatro primeros artículos del Concordato de 1851 entre tanto se llegase a la conclusión de un nuevo Concordato, donde quedaba regulada la confesionalidad del Estado y cuestiones como la enseñanza católica, y el 10, comprometiéndose a no legislar sobre materias mixtas o sobre aquellas que pudiesen interesar de algún modo a la Iglesia, sin previo acuerdo con la Santa Sede, fueron dos añadidos del nuncio apostólico que aceptó sin dificultad el ministro de Asuntos Exteriores. Estos dos artículos tendrían una importancia decisiva en las negociaciones posteriores ${ }^{77}$.El Concordato refrendaba ostensiblemente la oficialidad de la religión católica, el valor civil del matrimonio canónico, la adaptación de la enseñanza religiosa al ideario católico, la intervención de los obispos en materia de censura cuando se tratara de cuestiones de fe y costumbres. Igualmente, establecía la enseñanza religiosa obligatoria en todo el sistema educativo, el sostenimiento económico del clero, la exención de impuestos y el restablecimiento de los Fueros en cuanto a la jurisdicción de los Tribunales de Justicia. Las negociaciones encallaron en numerosas ocasiones sin dar mucho margen de confianza. Los cambios de los diferentes embajadores ante la Santa Sede: José de Yanguas Messía; Domingo de las Bárcenas y López-Mollinedo Mercado; Pablo de Churruca y Dotres; Joaquín Ruiz-Giménez Cortes; Fernando María Castiella y Maíz, en medio de las dificultades políticas, sociales y económicas supieron sortear los elementos más espinosos de las relaciones entre ambos Estados ${ }^{78}$.

En el preámbulo del Concordato se establece que: "En el nombre de la Santísima Trinidad. La Santa Sede Apostólica y el Estado español. animados del deseo de asegurar una fecunda colaboración para el mayor bien de la vida religiosa y civil de la Nación española, han determinado estipular un Concordato que, reasumiendo los Convenios anteriores y completándolos, constituya la norma que ha de regular las reciprocas relaciones de las Altas Partes contratantes, en conformidad con la Ley de Dios y la tradición católica de la Nación española".

Las relaciones entre la Iglesia y el Estado, en España se encontraron, entre mediados de los años 60 y principios de los 70, del siglo XX, con dos problemas de entidad. Por un lado, el privilegio del fuero que consagraba el concordato de 1953 producía

\footnotetext{
${ }^{76}$ Cf. P. MARTín de SANTA Olalla SALUdes, De la victoria al concordato: lasrelaciones Iglesia-Estado durante el primer franquismo, 1939-1953, Barcelona 2003.

77 Cf. CONVentio Inter SACtAMSedem et GuberniumHispanicum, en AAS 33(1941) 480-481.

${ }^{78}$ Cf. A. MARQuinA, "La Iglesia de España y el Régimen de Franco (1939-1975)", en E. Quintín y CÁRDENAS,Manual de Historia de la Iglesia. La Iglesia del siglo XX en España, Portugal y América Latina,Barcelona 1986, pp. 343ss.
} 
situaciones anómalas, pues sacerdotes de algún modo conectados con el movimiento terrorista de ETA no podían ser juzgados por las autoridades civiles, ya que el concordato exigía la autorización de los correspondientes obispos. Estos no siempre la otorgaban, dificultando el procedimiento penal y la acción policial. Por otro lado, a partir del Concilio Vaticano II, la Santa Sede había rogado a los distintos Estados que renunciaran al privilegio de Presentación o de poder intervenir en los temas y nombramientos de las autoridades eclesiásticas, incluidos obispos. Entre esos Estados estaba el Régimen del general Franco que, por privilegio concedido, tenía una notable intervención en el nombramiento de los obispos. Así pues, el detonante de la revisión del Concordato de 1953 fueron dos aspectos de máxima importancia: el libre nombramiento de Obispos y la igualdad de todos los ciudadanos frente a la administración de justicia ${ }^{79}$.

El Concilio Vaticano II constituyó un claro y evidente impulso para la transformación de las relaciones entre la Iglesia y el Estado en España. El Concordato de 1953, que era el marco jurídico a través del cual se regulaban los vínculos entre el catolicismo y el Régimen de Franco ${ }^{80}$, debía ser de nuevo renegociado al haber quedado obsoleto. Ante una paulatina tensión entre ambos estamentos, la llegada al ministerio de Asuntos Exteriores de Laureano López Rodó hizo viable la celebración de un primer encuentro tras el fracaso del llamado anteproyecto Agostino Casaroli y Antonio Garrigues Díaz-Cañabate de febrero de $1971^{81}$. Las cartas estaban echadas y el Concordato, en la praxis estaba, en vía muerta desde hacía varios años. Las posibles dificultades a la hora de su adaptación, llegada con los aires renovados del Concilio Vaticano II, cogió al Régimen con el paso cambiado, a lo que no pudo sustraerse.)

\section{Acuerdos Parciales con la Santa Sede y la Libertad Religiosa}

Los Acuerdos entre el Estado español y la Santa Sede de 1979 y la Ley de Libertad Religiosa de 1980, actualmente vigentes, son parte del legado en esta materia del ex presidente del Gobierno don Adolfo Suárez González. Los Acuerdos con la Santa Sede fueron firmados el 3 de enero de 1979 por el entonces secretario de Estado de la Santa Sede, el cardenal Jean Villot, y por el ex ministro de Asuntos Exteriores don Marcelino Oreja Aguirre.

Concretamente, se firmaron cuatro acuerdos: sobre Asuntos jurídicos, sobre Asuntos económicos, sobre Enseñanza y Asuntos culturales y sobre la Asistencia religiosa a las Fuerzas Armadas y el servicio militar de clérigos y religiosos. En el ámbito de la enseñanza, los Acuerdos de 1979 establecen que la acción educativa respetará el derecho fundamental de los padres sobre la educación moral y religiosa de sus hijos en el ámbito escolar y que, en todo caso, la educación que se imparta en los centros docentes públicos será respetuosa con

\footnotetext{
${ }^{79}$ Cf. J. R. Polo SABAU, Derecho y factor religioso. Textos y materiales, Madrid 2012, pp. 173-174.

${ }^{80}$ Cf. F. SeVILlano CAlero, "La delimitación del espacio católico: reflexiones y proyectos en el nuevo Estado franquista, 1936-1946", en G. SÁNCHEZ ReCIO (COORD.), La Internacional Católica: Pax Romana en la política europea de posguerra. Madrid [2005], pp. 51-74.

${ }^{81}$ Cf. P. Martín de SANTA Olalla SAludes, "La Santa Sede y la Conferencia Episcopal ante el cambio político en España (1975-1978)", en Revista española de Derecho canónico 69 (2012) 279-328.
} 
los valores de la ética cristiana. Además, se acuerda que los planes educativos en los niveles de Educación Preescolar, de Educación General Básica (EGB) y de Bachillerato Unificado Polivalente (BUP) y Formación Profesional, incluirán la enseñanza de la religión católica en todos los Centros de Educación, en condiciones equiparables a las demás disciplinas fundamentales, aunque no tendrá carácter obligatorio para los alumnos. En materia económica, el Estado se compromete a colaborar con la Iglesia católica en la consecución de su adecuado sostenimiento económico, con respeto absoluto del principio de libertad religiosa. Así, los acuerdos disponen que el Estado pueda asignar a la Iglesia católica un porcentaje del rendimiento de la imposición sobre la renta o el patrimonio neto u otra de carácter personal, por el procedimiento técnicamente más adecuado.

También fijan que la Santa Sede, la Conferencia Episcopal, las diócesis, las parroquias y otras circunscripciones territoriales, las Órdenes y Congregaciones religiosas y los Institutos de vida consagrada y sus provincias tendrán derecho a distintas exenciones fiscales.

Entre ellas, se encuentra la exención total y permanente de la Contribución Territorial Urbana de templos y capillas destinados al culto y edificios o locales anejos destinados a la actividad pastoral; de la residencia de obispos, canónigos y sacerdotes; de los locales destinados a oficinas de la Curia diocesana y a oficinas parroquiales; de los seminarios y universidades eclesiásticas que impartan enseñanzas propias de disciplinas eclesiásticas; y de casas o conventos de las diferentes órdenes, congregaciones e institutos de vida consagrada $^{82}$. Además, el sentido de la necesidad de establecer un nuevo marco de las relaciones entre la Iglesia y el nuevo orden constitucional, venía de muy atrás, cuando se quiso sustituir el Concordato de 1953 en la década de los años 70 del siglo XX. Esto no fue posible por las tensiones políticas que se produjeron en los últimos tiempos del régimen del general Franco con las bases y la jerarquía de la propia Iglesia católica.

\section{LIBERTAD RELIGIOSA EN ESPAÑA}

El tema de la libertad religiosa en España después casi de 40 años, desde la firma y ratificación de la Constitución en 1978 y, en especial, tras la firma de los acuerdos con distintas Confesiones religiosas en 1992. Desde ese momento se ha producido un gran cambio y evolución a favor de la igualdad religiosa, pero existen todavía muchas sombras. La discriminación legal ocurre aún en diversos ámbitos como la financiación; visibilidad pública de los órganos y representantes de las diversas entidades religiosas ${ }^{83}$; concesiones de suelo público para lugares de culto, etc. La Iglesia católica mantiene una serie de derechos que son ampliables y que requieren el resto de las demás Confesiones religiosas. La posible discriminación en el ámbito social afecta de diferente manera a cada una de las religiones que son minoritarias en nuestro país. España precisa mantener el principio de neutralidad

\footnotetext{
${ }^{82}$ Cf. Inter SACtAMSedem et HiSPAniam. SollemnesConventiones, “Concordato entre la Santa Sede y España, art. XX, 3", en AAS 45 (1953) 625-656.

${ }^{83}$ Cf. J. R. Polo SABAU, “Acotaciones al régimen jurídico de las entidades religiosas a la luz de la garantía constitucional de la libertad de asociación", en Cuadernos de DerechoPúblico 7 (2003/18)143-169.
} 
del hecho religioso de todas las entidades y Confesiones religiosas. El desconocimiento o malformación de la realidad provoca en numerosas ocasiones un cierto miedo y rechazo, lo que ha supuesto llevar adelante un gran debate en torno a la responsabilidad social de los Medios de comunicación a la hora de estudiar, profundizar y asumir los grandes temas relacionados con la identidad y diversidad religiosa. El lenguaje, la evangelización del mundo de la cultura, la formación continua son otras herramientas fundamentales para avanzar en la transmisión e interiorización de valores. La fe y la reflexión han de tenerse en cuenta a la hora de tomar opciones y asumir las decisiones de forma consciente, libre y responsable.

\subsection{Ley de Libertad religiosa de 6 de junio de 1967}

El Concilio Vaticano II aprobó la Declaración sobre la Libertad religiosa, en la Declaración Diginitatis humanae, donde afirma que "el derecho a la libertad religiosa está realmente fundado en la dignidad misma de la persona humana, tal como se conoce por la palabra de Dios revelada y por la misma razón. Este derecho de la persona humana a la libertad religiosa debe ser reconocido en el ordenamiento jurídico de la sociedad, de forma que se convierta en derecho civil" ${ }^{84}$.

Ante la declaración del Concilio Vaticano II, aparece la necesidad de ajustarlo a la realidad de las normas Fundamentales y es preciso modificar el artículo sexto del Fuero de los Españoles. Por esta razón, en la Ley Orgánica del Estado, de diez de enero de mil novecientos sesenta y siete, trasladaba dicha modificación a la Disposición adicional primera, en el artículo sexto del Fuero de los Españoles, que queda establecido de la siguiente manera: "La profesión y práctica de la religión católica, que es la del Estado español, gozará de protección oficial. El Estado asumirá la protección de la libertad religiosa, que será garantizada por una eficaz tutela jurídica que a la vez salvaguarde la moral y el orden público" $^{\prime 85}$. Evidentemente, el Régimen había dado un paso y lo había sometido a la aprobación previa de la Santa Sede. Esto llevó a abrir el camino para proceder desde la ley, para que, en el ordenamiento jurídico español, se incorporase el derecho civil de la libertad religiosa, y garantizado mediante la tutela del Estado, siempre que salvaguardase la moral, costumbres, orden público. Se salvaba la dignidad humana ${ }^{86}$.

En cumplimiento de este precepto, se promulgó la Ley de 28 de junio de 1967, reguladora del ejercicio del derecho civil en materia religiosa, y diversas normas complementarias de ejecución. Evidentemente el Régimen siguió en su línea ortodoxa con respecto a la doctrina de la Iglesia católica. A pesar de todas estas disposiciones, el tratamiento jurídico que el Estado español daba a la Iglesia católica en relación con las demás Confesiones religiosas era totalmente desigual. La Iglesia católica, poseía personalidad jurídica internacional, gozaba de todas las prerrogativas, se le mantenía una

\footnotetext{
${ }^{84}$ Cf. Concilio VAtiCANo II, “Declaración Dignitatishumanae” 2, en AAS 58 (1966) 929-946: especialmente 930931.

${ }^{85}$ Leyes Fundamentales del Reino, “Fuero de los Españoles, artículo 6”", BOE no 199 de 18-07-1945.

${ }^{86}$ Cf. J. HeRRANZ, La libertad religiosa en nuestra sociedad, Madrid 2006, pp. 17-24.
} 
posición privilegiada y el Estado español seguía inspirando su legislación en las normas de la Iglesia. De otro lado, las Confesiones religiosas acatólicas, aunque estaban reconocidas legalmente, tras su constitución en Asociaciones confesionales y adquisición de personalidad jurídica civil mediante su inscripción en el Registro de Asociaciones Confesionales no católicas y de los ministros de culto no católicos en España, recogido bajo el amparo del Ministerio de Justicia, pero no ostentaban el mismo tratamiento jurídico que la Iglesia católica, recortando y limitando todas sus actuaciones externas, ante el posible temor al peligro de la pérdida de la unidad espiritual y, por tanto, no disfrutaban sus creyentes, solos o asociados, de la auténtica libertad religiosa, a lo sumo, sólo de libertad de cultos o cierta tolerancia ${ }^{87}$. Eso no era lo que había pedido el Concilio Ecuménico Vaticano II. Sin duda, lo que asistieron a la novedad de la Ley $44 / 67$ del 28 de junio, como una ley de Libertad religiosa, debemos tener en cuenta que se trataba más bien de una ley Reguladora del derecho civil a la libertad en materia religiosa, no se puede admitir que nada tenía que ver con una auténtica moderna, democrática ley de Libertad religiosa.

Hay que recordar que, tras dicha promulgación, algunos templos de Iglesias acatólicas se vieron sorprendidos por diversas agresiones como el de la Iglesia Evangélica Española en la ciudad de Zaragoza ${ }^{88}$. Esto daba pie a pensar la intransigencia religiosa, como en otros aspectos, se vivía en la sociedad española de los años 60, del siglo XX.

La intransigencia religiosa era el fiel reflejo de la intransigencia política, social, económica y cultural que se alentaba y se reflejaba en aquellos años más bien duros y bien complicados, y que no daba alternativas para llevar experiencias de cualquier tipo que supusieran cambios profundos en el modus vivendi y en el modus operandi. A la misma Iglesia católica española le costó mucho tiempo aceptar, comprender y asimilar lo que el mismo Concilio había pedido en todos los planos. La omnipresencia de la Iglesia, lo era todo en el contexto social español y además rebatía cualquier posibilidad de diálogo posterior con los demás.

Eso fue un aspecto muy controvertido a la hora de iniciar diálogos ecuménicos entre las Iglesias y Confesiones cristianas, de una parte y que es conocido como diálogo ecuménico, como por la apertura necesaria con otras religiones, especialmente las del Libro, Judaísmo $^{89}$ e Islamismo ${ }^{90}$, y otras más, que se han ido asentado paulatinamente en nuestro

\footnotetext{
${ }^{87}$ Cf. Ley 44/1967 de 28 de junio de 1967, de Libertad religiosa, BOE no 156, de 1 de julio de 1967, pp. 91919194.

${ }^{88} \mathrm{Cf}$. Esto fue algo común ante la intransigencia de grupos sociales contrarios al reconocimiento de la ley.

${ }^{89}$ Cf. S. FerRARI, El espíritu de los derechos religiosos. Judaísmo, cristianismo e islam, Barcelona 2004.

90 Cf. L. Martín-Retortillo, "Reflexiones sobre los Acuerdos de cooperación del Estado con las federaciones evangélica, judía y musulmana, en los diez años de su vigencia”, en Revista Aragonesa de Administración Pública 12 (2003/23) 11-40; A. MONTILLA DE LA CALLE, "El problema del velo islámico en Europa y en España", en Anuario de Derecho Eclesiástico del Estado 20 (2004) 87-129.
} 
país, inscritas en el Registro de Entidades religiosas ${ }^{91}$ del Ministerio de Justicia, que van teniendo notorio arraigo y que se conoce como dialogo interreligioso. La colaboración entre la Iglesia y el Estado ${ }^{92}$, dentro de los países de nuestro entorno, es uno de los aspectos más decisivos para poder reconocer los derechos humanos. Es más, las dificultades que se puedan originar están ya fuera de lugar en los tiempos que corren.

\subsection{La Ley de Libertad religiosa de 24 de julio de 1980}

Hay que tener en cuenta que, la Ley de Libertad Religiosa apareció publicada en el Boletín Oficial del Estado del 24 de julio de 1980 y entró en vigor en agosto de ese mismo año. En dicha norma, que aún está en vigor, se establece que las creencias religiosas no constituirán motivo de desigualdad o discriminación y que ninguna de las confesiones religiosas tendrá carácter estatal.

Asimismo, se reconoce el derecho de toda persona a profesar las creencias religiosas que libremente elija; a reunirse públicamente con fines religiosos y a recibir e impartir enseñanza religiosa y a elegir para sí y para los menores no emancipados e incapacitados, bajo su dependencia, dentro y fuera del ámbito escolar, la educación religiosa y moral de acuerdo a sus convicciones. También dispone que el Estado, teniendo en cuenta las creencias religiosas, existentes en la sociedad española, establezca Acuerdos o Convenios de cooperación con las Iglesias, Confesiones y Comunidades religiosas inscritas en el Registro que por su ámbito y número de creyentes hayan alcanzado notorio arraigo en España. En este sentido, decreta que, en dichos Acuerdos o Convenios, y respetando siempre el principio de igualdad, se podrán extender a dichas Iglesias, Confesiones y Comunidades los beneficios fiscales previstos en el ordenamiento jurídico general para las entidades sin fin de lucro y demás de carácter benéfico. Asimismo, comprende el derecho de las Iglesias, Confesiones y Comunidades religiosas a establecer lugares de culto o de reunión con fines religiosos y crea en el Ministerio de Justicia una Comisión Asesora de Libertad Religiosa compuesta de forma paritaria por representantes de la Administración del Estado y de las confesiones $^{93}$. Esto ha supuesto un gran cambio en la consideración de los temas de calado religioso a la hora de enfrentar distintos puntos de vista y sensibilidades que se encuentran en todas las Confesiones y entidades religiosas.

\footnotetext{
91 Cf. S. CATAlÁ RuBio, "Algunos problemas que plantea el actual sistema de inscripción de las entidades religiosas", en Anuario de Derecho Eclesiástico del Estado 18 (2002) 495-508; J. MANTECón SANCHO, Los acuerdos del Estado con las confesiones acatólicas, Jaén 1995.

92 Cf. R. NAVARro-VAlls - R. PAlomino, Estado y religión, Barcelona $2003^{2}$.

${ }^{93}$ Cf. La Ley Orgánica 7/1980, de 5 de julio, de Libertad Religiosa dispuso en su artículo 8 la creación en el Ministerio de Justicia de la Comisión Asesora de Libertad Religiosa, con las competencias de estudio, informe y propuesta de todas las cuestiones relativas a la aplicación de dicha Ley Orgánica y particularmente, y con carácter preceptivo, la preparación y dictamen de los acuerdos o convenios de cooperación con las Confesiones religiosas, en BOE no 177, de 24-07-1980, pp. 16804-16805.
} 


\subsection{Comisión Asesora de libertad religiosa}

Esta comisión tiene como cometido lo siguiente:

En el BOE de fecha, 16 de diciembre de 2013, se ha publicado el Real Decreto 932/2013, de 29 de noviembre, por el que se regula la Comisión Asesora de Libertad Religiosa, norma por la que se crea la citada comisión y cuyas funciones ${ }^{94}$ son:

a) Conocer e informar preceptivamente los proyectos de acuerdos o convenios de cooperación a que se refiere el artículo 7 de la Ley Orgánica 7/1980, de 5 de julio.

b) Conocer e informar los proyectos de disposiciones de carácter general que afecten a la aplicación de la Ley Orgánica 7/1980, de 5 de julio.

c) Conocer e informar los proyectos de disposiciones de carácter general que afecten a la aplicación y desarrollo de los acuerdos celebrados entre el Estado español y las confesiones religiosas.

d) Conocer e informar los anteproyectos de ley y cualesquiera otras disposiciones generales de la Administración General del Estado que regulen materias concernientes al derecho de libertad religiosa.

e) Emitir informe sobre la declaración de notorio arraigo de las iglesias, confesiones o federaciones de las mismas.

f) Emitir informe de las cuestiones relacionadas con la inscripción y cancelación de las entidades religiosas, que le sean sometidas a su consulta.

g) Emitir informes sobre las normas que incidan en el ejercicio del derecho de libertad religiosa que hayan sido dictadas por las Comunidades Autónomas, que el Gobierno, a través del Ministro de Justicia, someta a su consulta.

h) Emitir informes sobre los asuntos concernientes a su ámbito de competencias que el Gobierno, a través del Ministro de Justicia, someta a su consideración.

i) Estudiar y presentar propuestas al Gobierno de cuantas medidas considere oportunas en el ámbito de la libertad religiosa, sin perjuicio de las competencias que la normativa vigente atribuya en la materia a otros órganos.

j) Elaborar y elevar anualmente un informe al Gobierno sobre la situación del derecho de libertad religiosa en España.

k) Recabar información sobre actuaciones de las Administraciones Públicas relacionadas con el desarrollo y ejercicio del derecho de libertad religiosa.

l) Cualquier otra función que, en el ámbito de sus competencias, se le atribuya por alguna disposición legal o reglamentaria ${ }^{95}$.

\footnotetext{
94 Cf. R. GARcía GARcía, La Comisión asesora de libertad religiosa: sus antecedentes, precedentes, discusión parlamentaria y regulación actual, Madrid 2003.

${ }^{95}$ Cf. Cf. BOE de 16 de diciembre de 2013, se ha publicado el Real Decreto 932/2013, de 29 de noviembre, por el que se regula la Comisión Asesora de Libertad Religiosa.
} 
La Comisión es un órgano consultivo del Gobierno en materia de libertad religiosa. Su labor es impulsar y promover de forma efectiva el derecho a la libertad religiosa, mediante el estudio, seguimiento, informe y propuestas relacionadas con este derecho. La Ley Orgánica de Libertad Religiosa dispuso en su artículo 8 la creación en el Ministerio de Justicia de la Comisión Asesora de Libertad Religiosa, con las competencias de estudio, informe y propuesta de todas las cuestiones relativas a la aplicación de dicha Ley Orgánica y particularmente, y con carácter preceptivo, la preparación y dictamen de los acuerdos o convenios de cooperación con las Confesiones religiosas. También puede informar, a solicitud del Ministerio de Justicia, las peticiones de inscripción en el registro de Entidades Religiosas ${ }^{96}$.

El Real Decreto 1890/1981, de 19 de junio, sobre constitución de la Comisión Asesora de Libertad Religiosa en el Ministerio de Justicia, estableció la regulación básica de la composición, organización y funcionamiento de dicha Comisión. De acuerdo con la referida autorización legal, advertida la necesidad de ajustar la composición de la Comisión a la estructura y competencias de los actuales Departamentos ministeriales y de clarificar y perfeccionar, a la luz de la experiencia adquirida en los últimos años, la organización y funcionamiento de la misma, se aprecia la conveniencia de dictar un nuevo Real Decreto que regule la Comisión Asesora de Libertad Religiosa ${ }^{97}$.

Tal Real Decreto fue posteriormente sustituido por el Real Decreto 1159/2001, de 26 de octubre ${ }^{98}$.La Ley Orgánica $7 / 1985^{99}$, de 5 de julio, de Libertad Religiosa insiste en esta actitud de cooperación al incorporar en su articulado, junto al desarrollo del contenido esencial del derecho de libertad religiosa que le compete en aplicación del artículo 81 de la Constitución española, determinados mecanismos para llevar a la práctica el mandato constitucional. Posteriormente ha visto la luz el Real Decreto 932/2013, de 29 de noviembre ${ }^{100}$, por el que se regula la Comisión Asesora de Libertad Religiosa. España cuenta con un sistema modélico respecto a la legislación sobre libertad religiosa. Es necesario poner de manifiesto que en nuestra sociedad han de establecerse unos principios éticos, morales y legales que pongan de manifiesto la defensa de este derecho constitucional y fundamental sobre la libertad religiosa.

\footnotetext{
${ }^{96}$ Cf.http://www.mjusticia.gob.es/cs/Satellite/es/1215197982464/Estructura_P/1215198297284/Detalle.htl Visto 04-05-2018.

${ }^{97}$ Era necesario adecuar a los tiempos la regulación realizada anteriormente.

${ }^{98}$ Cf. Real Decreto 1159/2001, de 26 de octubre, por el que se regula la Comisión Asesora de Libertad Religiosa, en BOE no 258, de 27 de octubre de 2001, pp. 39461-39462.

99 Cf. Ley Orgánica 7/1985, de 1 de julio, sobre derechos y libertades de los extranjeros en España, en BOE no 158, de 3 de julio de 1985, pp. 20824-20829.

${ }^{100}$ Cf. Real Decreto 932/2013, de 29 de noviembre, por el que se regula la Comisión Asesora de libertad Religiosas, en BOE no 300, de 16 de diciembre de 2013, pp. 98994-99002.
} 


\subsection{Un adelantado respecto a las relaciones Iglesia Estado: Dietrich Bonhoeffer}

Sería Dietrich Bonhoeffer, teólogo y pastor luterano, fue un líder religioso alemán que participó en el movimiento de resistencia contra el nazismo. Bonhoeffer, fue detenido y trasladado a prisión por la Gestapo, fue llevado al campo de concentración de Buchenwald en 1945 y posteriormente al de Flossenbürg, donde murió ejecutado en la horca, el 9 de abril de 1945. Defendió que la Iglesia y el Estado se han de relacionar mutuamente sin interferencias, ya que cada uno de ellos debe mantener sus propias misiones que son diferentes, pero al mismo tiempo complementaria entre sí. Se trata de un hombre muy educado, de la alta burguesía alemana, formado en la teología dogmática por una de las universidades más reputadas de Alemania, en Tubinga, un teórico del conocimiento con vocación docente, llamado a ocupar un lugar destacado en la cátedra universitaria de su especialidad, pero que de pronto, desvía su mirada hacia una parte del mundo desconocida e invisible para él y descubre un submundo de pobreza, marginación, sufrimiento y exclusión social que produce una profunda transformación en su manera de interpretar y vivir el cristianismo.

A partir de este momento, nada será igual. Ni su idea sobre sí mismo; ni su percepción de la Iglesia; ni su comprensión del mundo; ni la concepción de la teología como modo de interpretar la realidad. Estas experiencias produjeron en Dietrich un proceso de anonadamiento o kénosis, de abajamiento, de vaciamiento que le cambió la mirada sobre las cosas que le rodeaban transformando por completo su quehacer y su vivir. Su testimonio es, ante todo, profético porque supo cómo pocos actuar como un verdadero portavoz del Evangelio, manteniendo viva la esperanza para su pueblo en las condiciones más adversas posibles. Pero es también su carácter martirial porque su fidelidad inquebrantable le llevó a sufrir persecución, cárcel y muerte. Es un testimonio de humanidad, de opción decidida y defensa de todo lo auténticamente humano en medio de la barbarie, la injusticia y la opresión en medio de una sociedad rota y con claros signos de descomposición. La vida y obra de Bonhoeffer aparecen llenas de una existencia y un espíritu que hacen posible el disfrute pleno de un cristianismo comprometido ante las situaciones más imponderables ${ }^{101}$. Un hombre auténtico ${ }^{102}$.

Por eso llegaría a afirmar muchos años antes de la celebración del Concilio Vaticano II, que:"milagro y orden: he aquí los dos aspectos en los que se configura el Reino de Dios en la tierra, en los que se manifiesta escindido... El aspecto bajo el cual el reino de Dios se manifiesta como milagro lo llamamos Iglesia; y el aspecto bajo el cual el reino de Dios se manifiesta como orden lo llamamos Estado. El Reino de Dios en nuestro mundo no es otra cosa que la dualidad de Iglesia y Estado. Ambos se hallan necesariamente en relación. Ninguno de los dos existe sólo para sí. Cualquier intento por parte de uno de apoderarse del

\footnotetext{
${ }^{101}$ Cf.D. BonhoefFER, 40 días con DietrichBonhoeffer, Santander 2014.

${ }^{102}$ Cf. D. BonhOEFFER, Resistencia y sumisión, Salamanca 2001, p. 266; H. VALL, Iglesia e ideología nazi, Salamanca 1976, pp. 234-237; R. BETHGE, DietrichBonhoeffer. Esbozo de una vida, Salamanca 2004, pp. 4-5; G. HOURDIN, Bonhoeffer. Una Iglesia para mañana, Madrid 1972, pp. 101-128.
} 
otro desprecia esta relación del Reino de Dios en la tierra... La Iglesia limita al Estado, quien, a su vez limita a la Iglesia. Ambos deben permanecer conscientes de esta recíproca limitación, y deben sobrellevar esta tensa coexistencia, que nunca debe convertirse en interferencia. Sólo así se referirán ambos conjuntamente, nunca cada uno por su cuenta, al Reino de Dios, que tan maravillosamente se atestigua en esta doble manifestación ${ }^{\prime 103}$.

\section{BALANCE}

El constitucionalismo español, se podría determinar como aquel proceso, a través del cual el Estado español se ha dotado desde el año 1808 de una serie de normas constitucionales, Cartas otorgadas y otras que no llegaron a promulgarse. Esto se ha debido a las diversas convulsiones políticas españolas durante los siglos XIX y XX, mostrando las tensiones educativas, sociales, económicas y políticas que soportó la sociedad española ${ }^{104}$. Lo que conocemos como España, se ha definido de muchas y diferentes manera, en función de los distintos sistemas constitucionales de los que se ha dotado este país, desde 1808 hasta $1978^{105}$. Es necesario darnos cuenta de la realidad diferente, según las épocas y cómo han influido sobre la ideología determinada y dominante de cada situación. Cada una de esas definiciones, suponen un sistema político muy concreto para cada momento histórico, desde las Cortes de Cádiz ${ }^{106}$ hasta la Constitución de $1978^{107}$. Cádiz, supuso un inmenso avance que tuvo que romper con el régimen de la Monarquía absolutista.

La Constitución se puede admitir como la ley suprema de un país, es decir, la ley de leyes que incluye todas las normas fundamentales de un Estado, por la que regula su ordenamiento jurídico; la norma que está por encima de todas las normas y, a la que deben someterse todos los ciudadanos y órganos políticos; las leyes de las Cortes, Congreso y Senado; los decretos gubernamentales y las órdenes ministeriales que se desarrollen. Para juristas como Francisco Tomás y Valiente, sólo son auténticas constituciones, aquellas que están legitimadas democráticamente ${ }^{108}$.La auténtica peculiaridad constitucional española sería fundamentalmente, la derivada de un Régimen dictatorial que evolucionó a un sistema autoritario que se asentó en España en medio de un gran desinterés, cuando no de la falta de la solidaridad, de gran parte de las denominadas democracias europeas, o de nuestro entorno. Debe quedar claro, que el Régimen del general Francisco Franco, no tiene un espacio en esta historia constitucional, pues las Leyes Fundamentales se vieron, más bien como una Carta Fundamental otorgada. Por esta razón, la historia del nuestro constitucionalismo es siempre, la de la construcción avanzada y progresiva de la libertad en todas sus dimensiones y no la de su destrucción de la misma. En España, la cúpula de la Iglesia, a través de la Conferencia Episcopal Española (CEE), se ha mostrado especialmente

\footnotetext{
${ }^{103}$ D. BONHOEFfer, Venga a nosotros tu reino. Creer y Vivir, Salamanca 1985, pp. 110 y 113.

${ }^{104}$ Cf. C. VICÉn ANTOLín, Historia del Constitucionalismo español (1808-1979), Madrid 2004.

${ }^{105}$ Cf. F. TOMÁs Y VALIENTE, "La Constitución de 1978 y la historia del constitucionalismo español", en Anuario de Historia del Derecho Español 50 (1980) 721-751.

${ }^{106}$ Cf. I. RuIz RodríGUEZ, Cádiz 1812. Origen del constitucionalismo español, Madrid 2013.

${ }^{107}$ Cf. L. SÁNCHEZ AgESTA, Historia del constitucionalismo español (1808-1936), Madrid 1984.

${ }^{108}$ Cf. Ma PAz Alonso Romero, Francisco Tomás y Valiente: Memoria y legado de un maestro, Salamanca 2016.
} 
beligerante con las medidas de progreso social emprendidas por el Gobierno socialista, mostrando su cara más conservadora. Como dice el Evangelio: "Por sus hechos los conoceréis". Y, si se analizan sus hechos y sus declaraciones públicas, la Iglesia española, o por lo menos una gran parte de su Episcopado, parece estar inmersa en una cruzada para devolver a la "pagana" España a su fe católica ${ }^{109}$.Como hemos visto, a comienzos del siglo $X X$, España representaba el ejemplo por excelencia de una sociedad con "una religión única, dominante y coherente", una religión dirigida y seguida por fieles, obispos, órdenes religiosas y clero secular, que consideraba que la preservación absoluta del orden social era irrenunciable, dada la estrecha relación entre orden y religión en la historia de España. Por eso resistieron los vientos de la modernización y la secularización de forma tan fuerte. $Y$ levantaron un sólido dique frente a los individuos que disentían con sus opiniones y estilo de vida de ese orden que ellos anunciaban y amparaban.

Así se forjó la historia de un resentimiento constante entre clericalismo y anticlericalismo, orden y cambio, reacción y revolución que, agudizado en los años de la Segunda República, pero que provenía de los tiempos de la desamortización de Juan Álvarez Mendizábal y acabó en 1939, tras una sangrienta Guerra Civil que enfrentó a las dos Españas. Hoy todavía se hace denotar la clara intransigencia del anticlericalismo, muchas veces residual del siglo XIX, trasnochado y con poca solvencia social ${ }^{110}$.

La sombra de la persecución religiosa dura hasta la actualidad y se ha manifestado claramente en muchos momentos y situaciones de nuestros días. Ninguna investigación rigurosa y seria ha tratado de ocultar esa violencia anticlerical o de evitar su análisis e interpretación. La Iglesia hizo cuanto pudo y estuvo en su mano, cuestión nada fácil dentro de los márgenes del poder y que no pudo maniobrar del todo. Dicha persecución que ocurrió dentro de la década de los años treinta del siglo XX, se mantuvo en el inconsciente colectivo por décadas y generaciones, difíciles de superar. La comunidad cristiana mantuvo y asumió una opción posibilista y de ahí llevó y pilotó un gran trabajo de reconciliación ${ }^{111}$. La realidad republicana consiguió exasperar a muchos ciudadanos que habían creído en ella, pero las primeras embestidas contra la Iglesia católica, denotaban ya por donde discurrirían las cosas en el futuro. Las relaciones Iglesia Estado han sido siempre una de las cuestiones clave en la historia de España y un dato indispensable para poder explicar muchos de los acontecimientos sociales, políticos, ideológicos, entre otros, que han ocurrido en nuestro país $^{112}$. De ahí su influencia mutua y sus repercusiones en todos los campos de la vida. A comienzos del siglo XX, la Iglesia católica no contemplaba en el horizonte graves alteraciones en su privilegiada posición. Pese a las desamortizaciones y las revoluciones liberales del siglo

\footnotetext{
${ }^{109}$ Cf. J. M. VAgGione, “la nueva línea política del Vaticano”, en Le Monde diplomatique en español abril de 2008, pp. 4-5.

${ }^{110} \mathrm{Cf}$. http://www.juliancasanova.es/iglesia-catolica-estado-y-conflictos-sociales-y-culturales-en-la-historia-deespana-del-siglo-xx/ Visto 04-05-2018.

${ }^{111}$ Cf. R. NAvarro VAlls, "Acerca de las relaciones Iglesia-Estado", en El País 11-06-2004 y https://elpais.com/diario/2004/06/11/opinion/1086904809 850215.html Visto 04-05-2018.

${ }^{112}$ Cf. J. M. CUENCA TORIBIO, "Relaciones Iglesia y Estado en la España democrática", en Revista de Fomento Social $40(1994 / 194) 241-261$.
} 
XIX, el estado confesional había permanecido intacto. La Restauración de la monarquía borbónica, a partir de 1875, le abrió nuevos caminos de poder social e influencia y la aristocracia terrateniente y las buenas familias de la burguesía dieron nuevos impulsos al renacimiento católico con numerosas donaciones de edificios y rentas a las Órdenes y Congregaciones religiosas ${ }^{113}$.

El Concordato de 1953, que se ve hoy como un anacronismo histórico, contribuyó a impulsar la presencia de la Iglesia en el mundo de las realidades educativas, culturales y sociales de su tiempo ${ }^{114}$.

Sería el 27 de agosto de 1953 se firma un concordato entre la Santa Sede y España impulsado por el ministro del Exterior Martín Artajo, que será clave para la política interior y para el reconocimiento internacional de España. En el concordato se reconoce la oficialidad del catolicismo, la obligatoriedad de la enseñanza religiosa, el reconocimiento pleno, a efectos civiles, del matrimonio canónigo, la inmunidad judicial y exenciones tributarias para los clérigos, y una dotación económica para el clero que será revisable según el nivel de vida. El régimen, que tiene como religión oficial la católica, cambia los símbolos fascistas por el nacionalcatolicismo, una ideología ultraconservadora y tradicionalista. El artículo I de este Concordato, estipula que la Religión Católica, Apostólica, Romana sigue siendo la única de la nación española, y gozará de los derechos y de las prerrogativas que le corresponden en conformidad con la Ley Divina y el Derecho canónico. Por su parte, Franco consigue de Pío XII el derecho de representación de obispos, aunque la Santa Sede puede nombrar libremente a los obispos auxiliares ${ }^{115}$ y el Fuero eclesiástico.

\section{CONCLUSIÓN}

Las relaciones Iglesia-Estado, la historia del Constitucionalismo español son temas muy debatidos a lo largo de nuestra historia de los últimos doscientos años. Los grandes vaivenes de la política y los derechos constitucionales bailaron al son que les marcaban los avatares sociales. Las condiciones sociales por las que atravesó España durante todo este tiempo no fueron nada fáciles y los equilibrios que tuvo que llevar adelante influyeron, según el momento, de manera acertada o desacertadamente. Igualmente, la realidad económica marcó muchos de los pasos realizados.

\footnotetext{
${ }^{113}$ Cf. R. Navarro Valls, "Acerca de las relaciones Iglesia-Estado", en El País 11-06-2004 y https://elpais.com/diario/2004/06/11/opinion/1086904809 850215.html Visto 04-05-2018.

${ }^{114}$ Cf. Ma BlAnCo FeRnÁNDEZ, La libertad religiosa en el derecho español: gestión de Antonio Garrigues en la revisión del Concordato de 1953 (1967-1970),Navarra 2006.

${ }^{115}$ Cf. A. MARquina, La diplomacia vaticana y la España de Franco (1936-1945), Madrid 1983, pp. 392-415, doc. 40-47.
} 


\section{En cuanto al tema del constitucionalismo:}

1. La inestabilidad constitucional se debió a que algunas de ellas estuvieron en funcionamiento y tuvieron vigencia en diversas épocas como es el caso de la de 1812, que se promulgó y se derogó en varias ocasiones. Esto supuso un gran desasosiego para todos los implicados.

2. Estando vigente alguna Constitución aparecieron alternativas, posibilidades, intentos que tenían por finalidad su sustitución o al menos correcciones de la misma. Es el caso de la de 1845. No siempre se ha estado de acuerdo, en apreciar las bondades que la misma sociedad demandaba.

3. La inestabilidad constitucional de debió en parte a las numerosas ocasiones en las que la inestabilidad de la política española hacia gala de su presencia, bien con conjuras internas al propio sistema político o por recelos a intentonas golpistas durante los períodos democráticos.

4. La intolerancia de los partidos políticos que desean introducir en los textos constitucionales sus posturas partidarias o recogidos en los programas electorales, algo que nunca ninguno aceptó bajo ningún concepto, por ninguno de los partidos del arco político.

5. Ha sido siempre muy difícil que hubiese un grado de aceptación mínima, por parte de la población, de los ciudadanos no han llegado a tener una buena afección o intensa devoción. Se han visto más como auténticos factores de un grave riesgo, que acentuaban más del disenso y enfrentamiento que el vínculo de unión y armonía social.

\section{En cuanto al tema de la libertad religiosa:}

6. La libertad religiosa fue concebida como la primera de las libertades de la persona, concebida desde la identidad y dignidad de la misma. No siempre esto se ha dado en nuestra realidad constitucional y en nuestras costumbres

7. En España la cuestión religiosa ha sido piedra arrojadiza de unos contra otros. Sin duda, ha sido una de las asignaturas pendientes y sin conseguir una solución digna, satisfactoria y equilibrada. Hemos pasado de un extremo a otro.

8. El conflicto permanente acerca de la financiación que ha sido fluctuante en casi todas las constituciones derivó en falta de consideración de la Administración Pública, en momentos alternativos, respecto a los miembros de la Iglesia.

9. Los conceptos tan controvertidos como confesionalidad, laicismo que fueron desastrosos para nuestra historia, hoy se valoran más positivamente los términos de aconfesionalidad y laicidad, aspectos que encuadran mejor nuestra realidad actual.

10. Las relaciones entre la Iglesia y el Estado, establecidas en nuestro marco jurídico, plantean la libertad religiosa como un derecho integrado constitucionalmente y que 
es muy positivo y en el que todos los ciudadanos se pueden amparar y acoger, sea cual sea su credo o religión.

Un decálogo que nos permite atisbar cómo fueron, cómo son y cómo serán las relaciones Iglesia Estado en un marco constitucional que preserva el derecho de la libertad religiosa

Es bueno recordar las palabras dirigidas por el papa Pablo $\mathrm{VI}$, a los reyes de España, con ocasión del viaje realizado a Roma el 10 de febrero de 1977: "Por vuestra eficaz intervención personal en dicho campo, os reiteramos, Majestad, nuestro aprecio $y$ agradecimiento sinceros, a la vez que os aseguramos que la Iglesia no busca privilegios, sino espacio suficiente de libertad en el que poder desarrollar su misión evangelizadora y ofrecer a la sociedad el servicio de su colaboración para el bien común de los españoles. Confiamos que ese espacio, con sus prácticas implicaciones en lo social, no le faltará nunca"116.

Es muy clara la postura papal y que refleja lo que desea la Iglesia en su servicio a la sociedad española.

\section{BIBLIOGRAFÍA}

\section{MONOGRAFÍAS}

Alonso Romero, Ma. P., Francisco Tomás y Valiente: Memoria y legado de un maestro, Salamanca 2016.

Álvarez TARDío, M., Anticlericalismo y libertad de conciencia: política y religión en la segunda República española, 1931-1936, Madrid 2002.

Amigo Vallejo, C., "Una transición olvidada", en La Constitución Española de 1978 en su XXV Aniversario, Barcelona 2003, pp. 461-465.

BÉCARUD, J., La Segunda República española, Madrid 1967.

BETHGE R., DietrichBonhoeffer. Esbozo de una vida, Salamanca 2004.

Blanco Fernández, Ma., La libertad religiosa en el derecho español: gestión de Antonio Garrigues en la revisión del Concordato de 1953 (1967-1970),Navarra 2006.

BLANCO VALDÉS, R. L., Introducción a la Constitución de 1978, Madrid 2006.

BONHOEFFER, D., Venga a nosotros tu reino. Creer y Vivir, Salamanca 1985.

BONHOEFFER, D., Resistencia y sumisión, Salamanca 2001.

\footnotetext{
${ }^{116}$ Cf. PABLo VI, “Discurso del papa Pablo VI a sus Majestades los reyes de España”, en ASS 69 (1977) 153-155.
} 
BONHOEFFER, D., 40 días con DietrichBonhoeffer, Santander 2014.

CASANOVA AgUILAR, I., Las constituciones no promulgadas de 1856 y 1873, Madrid 2008.

Concordato celebrado en 1753 entre las cortes de Roma y Madrid, Imprenta Antonio Pérez de Soto, Madrid 1763.

Constituyentes de la II Repúblicaespañola, Pamplona 1975.

DE MEER, F., La cuestión religiosa en las Cortes

Díez-Picazo, L.- Perales, A. E., La Constitución de 1978, Madrid 2008.

Escudero, J. A., Curso de historia del derecho, Madrid 2012.

Fernández-Coronado González, A., Estado y confesiones religiosas: un nuevo modelo de relación: los pactos con las confesiones, leyes 24, 25 y 26 de 1992, Madrid 1995.

Fernández-Coronado González, A. (DiR.). El derecho de la libertad de conciencia en el marco de la Unión Europea: pluralismo y minorías. Madrid 2002.

FERNÁNDEZ MIRANDA, T., El hombre y la sociedad, Madrid 1966.

Fernández Riera, M., Rosario de Acuña y Villanueva. Una heterodoxa en la España del Concordato, Gijón 2009.

FERRARI, S., El espíritu de los derechos religiosos. Judaísmo, cristianismo e islam, Barcelona 2004.

Ferrer Ortiz, J. (CoORd.), Derecho eclesiástico del Estado español, Pamplona $1996^{4}$.

FRÍAS GARCíA, Mạ DEL C., Iglesia y Constitución: la jerarquía católica ante la Il República, Madrid 2000.

García GarcíA, R., La Comisión asesora de libertad religiosa: sus antecedentes, precedentes, discusión parlamentaria y regulación actual, Madrid 2003.

GARCíA-PARDO, D., El sistema de acuerdos con las confesiones minoritarias en España e Italia, Madrid 1999.

Giménez Martínez, M. Á., El Estado franquista. Fundamentos Ideológicos, bases legales y sistema institucional, Madrid 2014.

GonzÁlez-Ares, J. A., Leyes constitucionales españolas 1808-1978, Santiago de Compostela 2011. 
GonzÁlez-ARES, J. A., Las constituciones de la España contemporánea. De Estatuto de Bayona a las Leyes Fundamentales del franquismo, Santiago de Compostela 2010.

González Casanova, J. A., Federalismo i autonomía a Catalunya (1868-1938), Barcelona 1974.

GonzÁleZ -DoriA, F., Historia de las Constituciones de Godoy a Suárez, Madrid 1986.

Gutiérrez del Moral, M. J. - CañIVAno Salvador, M. A., El Estado frente a la libertad de religión: jurisprudencia constitucional española y del Tribunal Europeo de Derechos Humanos, Barcelona 2003.

HeRRANZ, J, La libertad religiosa en nuestra sociedad, Madrid 2006.

HouRDIN, G., Bonhoeffer. Una Iglesia para mañana, Madrid 1972.

JULIÁ, S., La Constitución de 1931, Madrid 2009.

JuLIÁ, S. - PÉreZ, J. - VALDEÓN, J., Historia de España, Madrid 2008.

KELSEN, H., Teoría general del Estado, Granada 2002.

Llamazares Fernández, D., Derecho de libertad de conciencia l, Libertad de conciencia y laicidad, Madrid $2002^{2}$.

MANTECón SANCHO, J., Los acuerdos del Estado con las confesiones acatólicas, Jaén 1995.

Marcuello Benedicto, J. I., La Constitución de 1845, Madrid 2007.

Marhuenda, F. -Zamora García, F. J., Fundamentos de Derecho Constitucional, Madrid 2016.

MarquINA, A., La diplomacia vaticana y la España de Franco (1936-1945), Madrid 1983.

Martín de Agar, J. T., Raccolta di Concordati 1950-1999, Ciudad del Vaticano 2000.

Martín, Ma del M.- Salido, M.- Vázquez García-Peñuela, J. Mą, Derecho y religión, Granada 2016.

Martínez de Pisón CaVero, J., Constitución y libertad religiosa en España, Madrid 2000.

Martín de Santa Olalla Saludes, P., De la victoria al concordato: las relaciones Iglesia-Estado durante el primer franquismo, 1939-1953, Barcelona 2003.

Martín de Santa Olalla Saludes, P., La Iglesia que se enfrentó a Franco: Pablo VI, la Conferencia Episcopal y el Concordato de 1953, Madrid 2005.

Navarro-Valls, R. - Palomino, R., Estado y religión, Barcelona $2003^{2}$. 
Navas Castillo, A. - Navas Castillo, F., El Estado Constitucional, Madrid 2009.

Ollero, A., España, ¿un Estado laico? La libertad religiosa en perspectiva constitucional, Madrid 2005.

PALOMINO, R., Religión y derecho comparado, Madrid 2007.

Pérez Ledesma, M., La Constitución de 1869, Madrid 2010.

Polo SABAU, J. R., Derecho y factor religioso. Textos y materiales, Madrid 2012.

Pro RUIZ, J., El Estatuto Real y la Constitución de 1837, Valencia 2010.

Puy Muñoz, F. (COORD.), Los derechos en el constitucionalismo histórico español Santiago de Compostela 2002.

Ruiz Rodríguez, I., Cádiz 1812. Origen del constitucionalismo español, Madrid 2013.

SÁNCHEZ AgeSTA, L., Historia del constitucionalismo español (1808-1936), Madrid 1984.

SOlÉ TURA, J. - AJA, E., Constituciones y períodos constituyentes en España (1808- 1936), Madrid $1977^{21 r}$.

TomÁs VillarroyA, T., Breve historia del constitucionalismo español, Madrid 1982.

Torres del Moral, A., Constitucionalismo histórico español, Madrid 2012.

TorRes del Moral, A., Estado de derecho y democracia de partidos, Madrid 2012.

VALL, H., Iglesia e ideología nazi, Salamanca 1976.

Varela Suanzes-Carpegna, J., La Constitución de 1876, Madrid 2009.

VICÉn ANTOLín, C., Historia del Constitucionalismo español (1808-1979), Madrid 2004.

Zamora García, F. J., Relaciones Iglesia-Estado en la España del Frente Popular, Madrid 2017.

Zamora Rodríguez, T. - Zamora García, F. J. - Rodríguez Fernández, J. -Marhuenda García, F. CANOSA USERA, R. -GONZÁlEZ RIVAS, J. J., El constitucionalismo frustrado. Proyectos españoles de 1834 a 1976, Madrid 2014.

\section{ESTUDIOS}

ConCilio Vaticano II, "Declaración Dignitatishumanae" 2, en AAS 58 (1966) 929-946: especialmente 930-931. 
Busto SAIZ, J. R., "El diálogo interreligioso en la construcción de Europa”, en TOMÁs MoRALES, S. de - Vaquero lafuente, E. - Valle López, J. (COORdS.), El día de Europa: presente y futuro de la Unión Europea: Actas de las I Jornadas en conmemoración del día de Europa de la Universidad Pontificia Comillas de Madrid, Madrid, 8 de mayo de 2002, Madrid 2003, pp. 3343.

Cantos Casenave, M. - Ramos Santana, A., "Las Cortes de Cádiz y el primer liberalismo. Elites políticas, ideologías, prensa y literatura. Aportaciones y nuevos retos", en Revista Ayer 22 (2012/85) 23-47.

CATALÁ RUBio, S., "Algunos problemas que plantea el actual sistema de inscripción de las entidades religiosas", en Anuario de Derecho Eclesiástico del Estado 18 (2002) 495-508.

Celador Angón, O., "Notas para una interpretación sistemática del artículo 6 del Tratado de la Unión Europea en materia de libertad de conciencia", en Derechos y Libertades 8 (2003/12) 141-177.

Cole DuRHAM, W., "La importancia de la experiencia española en las relaciones Iglesia-Estado para los países en transición", en J. MARTínEZ TORRÓN, (COORD.), Estado y religión en la Constitución española y en la Constitución Europea, Actas del Seminario Internacional Complutense celebrado en la Facultad de Derecho de la Universidad Complutense, Madrid, 14 de mayo de 2004, Granada 2006, pp. 43-68.

ContrerasCasado, M. - Montero Gibert, J. R., "Una constituciónfrágil: revisionismo y reformaconstitucional en la II Repúblicaespañola", en Revista de DerechoPolítico 6 (19811982/12) 23-63.

Conventio InTer Sactam Sedem et Gubernium Hispanicum, en AAS 33(1941) 480-481.

CuenCA ToRiBıo, J. M., "Relaciones Iglesia y Estado en la España democrática", en Revista de Fomento Social 40 (1994/194) 241-261.

De la Cueva, J., "El anticlericalismo en la SegundaRepública y la Guerra Civil”, en E. La ParraM. Suárez Cortina (Eds.), El anticlericalismo españolcontemporáneo, Madrid, 1998, pp. 211301.

De la Cueva, J., "El laicismo republicano: tolerancia e intolerancia religiosa en la SegundaRepública”, en Melanges de la Casa de Velázquez, 44, (2014/1) 89-109.

Díaz MercháN, G., "El derecho a la libertad religiosa y la Constitución de 1978: en el XXV aniversario de la Constitución", en Constitución Española de 1975 en su XXV Aniversario, Barcelona 2003, pp. 511-520.

García GarcíA, R., "El derecho de asociación en la historia de derecho eclesiástico: reconocimiento y regulación jurídica de las confesiones religiosas en España: decreto de 1 de noviembre de 1868; Ley de 30 de junio de 1887 y Ley de 2 de junio de 1933 relativa a 
confesiones y congregaciones religiosas", en Anuario de Derecho Eclesiástico del Estado 22 (2006) 161-202.

García Prous, C., "Libertad y tolerancia religiosa en la Constitución de 1876", en BulLón DE MendozA, A.-Togores. L. E. (Eds.), Cánovas y su Época: Actas del Congreso, Madrid 20-22 noviembre de 1997, Actas I (1999) 519-532.

Gómez GarcíA, P., "El laicismo visto en la teoría, en la ley y en la práctica política”, en Ensayos de Filosofía, no 5, 2017.

GonzÁlez-VARAS IbáÑEZ, A., "Las innovaciones de la carta de derechos fundamentales de la Unión Europea en materia de libertad religiosa", en Anuario de la Facultad de Derecho de Ourense 1 (2002) 271-288.

Inter Sactam Sedem et Hispaniam. Sollemnes Conventiones, "Concordato entre la Santa Sede y España, art. XX, 3", en AAS 45 (1953) 625-656.

LeAl Adorna, Ma del M., "Los principios del derecho eclesiástico según la interpretación de la doctrina española", en Anuario de Derecho Eclesiástico del Estado, 17 (2001) 35-100.

LEY 2 de junio de 1933, sobre Régimen de la Confesiones y congregaciones religiosas, Gaceta de Madrid de 3 de junio de 1933, no 154, pp. 1651-1653.

LEY 44/1967 de 28 de junio de 1967, de Libertad religiosa, BOE no 156, de 1 de julio de 1967, pp. 9191-9194.

LEY ORGÁNICA 7/1985, de 1 de julio, sobre derechos y libertades de los extranjeros en España, en BOE no 158, de 3 de julio de 1985, pp. 20824-20829.

LEY ORGÁNICA 7/1980, de 5 de julio, de Libertad Religiosa dispuso en su artículo 8 la creación en el Ministerio de Justicia de la Comisión Asesora de Libertad Religiosa, en BOE no 177, de 24-07-1980, pp. 16804-16805.

Leyes Fundamentales del Reino, “Fuero de los Españoles, artículo 6”", BOE no 199 de 18-071945.

Lombardía, P. - Fornés, J., "El Derecho Eclesiástico", en Ferrer Ortiz, J., (CoORd.), Derecho Eclesiástico del Estado español, Pamplona 2007, pp. 21-52.

Llamazares Fernández, D., "Laicidad, libertad de conciencia y acuerdos del Estado con las confesiones Religiosas", en Llamazares Fernández, D. (DIR), Libertad de Conciencia y Laicidad en las Instituciones y Servicios Públicos, Madrid 2005, pp. 7-32.

MarquinA, A., "La Iglesia de España y el Régimen de Franco (1939-1975)", en E. Quintín Y CÁrdenas, Manual de Historia de la Iglesia. La Iglesia del siglo XX en España, Portugal y América Latina, Barcelona 1986, pp. 343ss. 
Martín de Santa Olalla Saludes, P., "La Santa Sede y la Conferencia Episcopal ante el cambio político en España (1975-1978)", en Revista española de Derecho canónico 69 (2012) 279328.

Martín García, Ma del M., "Cooperación económica estatal con las confesiones religiosas, libertad religiosa y aconfesionalidad", en Anuario de Derecho Eclesiástico del Estado 16 (2000) 309-339.

Martín-Retortillo, L., "Reflexiones sobre los Acuerdos de cooperación del Estado con las federaciones evangélica, judía y musulmana, en los diez años de su vigencia", en Revista Aragonesa de Administración Pública 12 (2003/23) 11-40.

MARTín SÁnCHEZ, I., "La laicidad positiva y su reflejo en los Estados miembros de la Unión europea", en El Derecho Eclesiástico a las Puertas del Siglo XXI: libro homenaje al profesor Juan Goti Ordeñana, Madrid 2006, pp. 265-298.

MARTíneZ DE CODES, R. Ma., "La religión y la nueva Constitución para Europa", en Anuario de Derecho Eclesiástico del Estado 21 (2005) 39-47.

Martínez JiméneZ, Ma. J., "Relaciones Iglesia-Estado. El Concordato de 1753", en Hispania Sacra 52 (2000/105) 301-310.

MeER, F. DE, "De la república laica a la monarquía parlamentaria aconfesional, pasando por un Estado católico", en C. IzQuierdo - C. Soler (Eds.), Cristianos y Democracia, Pamplona 2005, pp. 169-189.

Molero Pintado, A., "Laicismo y enseñanza durante la Segunda República Española", en D. LLAMAZARES FERNÁNDEZ (ED.), Estado y Religión: proceso desecularización y laicidad: homenaje a don Fernando de los Ríos, Madrid 2001, pp. 141-164.

MinISTERIO DE ESTADO, Ratificación del Concordato de 1851, en Gaceta de Madrid no 6146 (1205-1851), pp. 1-4.

Montilla de la Calle, A., "El problema del velo islámico en Europa y en España", en Anuario de Derecho Eclesiástico del Estado 20 (2004) 87-129.

NAVARRo-Valls, R., "El principio de cooperación y la laicidad del Estado", en J. MartínezTORRÓN, J. (ED.), Estado y Religión en la Constitución Española y en la Constitución Europea: Actas del Seminario Internacional Complutense celebrado en la Facultad de Derecho de la Universidad Complutense, Madrid, 14 de mayo de 2004, Granada 2006, pp. 31-42.

NAVARRo-VAlls, R., "Justicia constitucional y factor religioso", en Estudios Jurídicos en Homenaje al Profesor Vidal Guitarte, Vol. II Castellón de la Plana 1999, pp. 691-700. 
Nieto NúÑEz, S. - CoRRAl SAlVAdor, C., "La garantía de la enseñanza de la religión en los Estados de la Unión Europea y candidatos a ella", en Anuario de Derecho Eclesiástico del Estado 19 (2003) 305-343.

Nieto SoRIA, J. M., "El pontificado de Martín V y la ampliación de la soberanía real sobre la Iglesia castellana (1417-1431)", en La España Medieval 17 (1994) 117-122.

Ollero Tassara, A., "Laicidad y laicismo en el marco de la Constitución española", en Ollero TASSARA, A.- HeRmidA del LlANO, C. (CoORdS.), La libertad religiosa en España y en el Derecho comparado, Madrid 2012, pp. 17-31.

PABLo VI, "Discurso del papa Pablo VI a sus Majestades los reyes de España", en ASS 69 (1977) 153-155.

Polo Sabau, J. R., "Acotaciones al régimen jurídico de las entidades religiosas a la luz de la garantía constitucional de la libertad de asociación", en Cuadernos de Derecho Público 7 (2003/18)143-169.

ReAL DeCRETO 1159/2001, de 26 de octubre, por el que se regula la Comisión Asesora de Libertad Religiosa, en BOE no 258, de 27 de octubre de 2001, pp. 39461-39462.

ReAl DeCRETo 932/2013, de 29 de noviembre, por el que se regula la Comisión Asesora de libertad Religiosas, en BOE no 300, de 16 de diciembre de 2013, pp. 98994-99002.

ROBLESMUÑOz, C., "El Vaticano, el nuncio y losobisposespañoles ante la República de abril de 1931", en J. DE LA CUEVA - F. MONTERO (EDS.), Laicismo y catolicismo. Elconflictopolíticoreligioso en la SegundaRepública, Alcalá de Henares 2009, pp. 129-158.

RoBlesMuÑoz, C., "Alcalá Zamora: un republicanodemócrata y un cristiano", en Hispania Sacra, 64, (2012/1) 69-148.

RosselL, J., "El concepto y contenido del derecho de libertad religiosa en la doctrina científica española y su incidencia en la jurisprudencia del Tribunal Constitucional", en Anuario de Derecho Eclesiástico del Estado 15 (1999) 87-128.

SeVIllano Calero, F., "La delimitación del espacio católico: reflexiones y proyectos en el nuevo estado franquista, 1936-1946", en SÁNCHEZ RECIO, G. (COORD.), La Internacional Católica: Pax Romana en la política europea de posguerra. Madrid [2005], pp. 51-74.

TomÁs y VAliente, F., "La Constitución de 1978 y la historia del constitucionalismo español", en Anuario de Historia del Derecho Español 50 (1980) 721-751.

VAGGIONE, J. M., "la nueva línea política del Vaticano", en Le Monde diplomatique en español abril de 2008, pp. 4-5. 
Varela Suanzes-Carpegna, J., "La Constitución de 1978 en la Historia Constitucional española", en Revista Española de Derecho Constitucional 23 (2003/69) 31-67.

Varela Suanzes-Carpegna, J., "La Constitución de Cádiz y el liberalismo español del siglo XIX", en Revista de las Cortes Generales 4 (1987/10) 27-109.

\section{WEBGRAFÍA}

http://www.congreso.es/portal/page/portal/Congreso/Congreso/Hist Normas/ConstEsp181 2 1978/Const1812 Visto 04-05-2018.

http://www.congreso.es/portal/page/portal/Congreso/Congreso/Hist Normas/ConstEsp181 2 1978/Const1837 Visto 04-05-2018.

http://www.congreso.es/portal/page/portal/Congreso/Congreso/Hist Normas/ConstEsp181

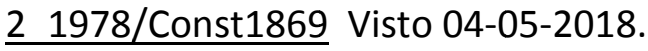

http://www.congreso.es/portal/page/portal/Congreso/Congreso/Hist Normas/ConstEsp181 2 1978/Const1876 Visto 04-05-2018.

http://www.cervantesvirtual.com/obra-visor/la-primera-constitucin-espaola---el-estatutode-bayona-0/html/ffc6353a-82b1-11df-acc7-002185ce6064 4.html Visto 04-05-2018.

http://pares.mcu.es/ParesBusquedas20/catalogo/description/5650557Visto 14-12-2018.

http://www.nunciaturapostolica.es/nunciatura-es.html Visto 04-05-2018.

http://www.andalan.es/?p=12806 Visto 04-05-2018.

http://www.mjusticia.gob.es/cs/Satellite/es/1215197982464/Estructura_P/1215198297284 Detalle.htl Visto 04-05-2018.

http://www.juliancasanova.es/iglesia-catolica-estado-y-conflictos-sociales-y-culturales-enla-historia-de-espana-del-siglo-xx/ Visto 04-05-2018.

https://elpais.com/diario/2004/06/11/opinion/1086904809 850215.html Visto 04-05-2018.

This work is licensed under a Creative Commons Attribution 4.0 Unported License 